\title{
DPSPU $62-30-38$
}

RECORDS ADMINISTRATION

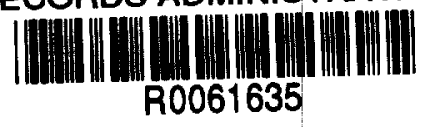

MARK VII-A FUEL SLUGS

Computer Surveillance of Crystallographic Orientation

R. S. Wood, Jr.

Sovannah River Plant

E. I. du Pont de Nemours and Company

Aiken, South Carolina

November 1962

To be presented at the X-Ray Diffraction

Conference on Preferred Orientation, at

Bridgeport, Conneçticut, in December 1962.

Publisher is requested to include this acknowledgment:

The information contained in this article

was developed during the course of work

under contract $\operatorname{AT}(07-2)-1$ with the

U. S. Atomic Energy Commission. 


\section{Introduction}

Dimensional stability of natural uranium fuel slugs during irradiation is important to continuous reactor operation. Because uranium exhibits an anisotropic growth property during irradiation, a method is needed to measure crystallographic orientation of uranium in fuel slugs and to relate this to dimensional stability during irradiation.

$\mathrm{X}$-ray diffraction techniques are being used routinely at the Savannah River Plant to measure the crystallographic orientation of Mark VII-A production slugs. Orientation of each of ten selected planes is compared with that which would be exhibited if crystals were oriented randomly, and a Growth Index ${ }^{I, 2}$ is calculated as a measure of the dimensional stability to be expected.

This report describes computer programs developed for data preparation, statistical analysis, and presentation of the $\mathrm{X}$-ray diffraction information.

Period Covered: April 1961 through June 1962.

\section{Summary}

Natural uranium fuel slugs are produced by a controlled process and definite averages and standard deviations exist for X-ray diffraction data. A change in a production variable, such as heat treatment, is readily discernible through statistical quality control.

Programs for the IBM 1401 computer have been developed which compute the average values and 3-sigma limits for Texture Coefficient and G3 Growth Index data. This information is updated weekly and is plotted by the computer in the form of average $(\overline{\bar{X}})$ and range $(R)$ charts. Each month an Exception Report and a G3 Index are computed. These show only those charts which had $\bar{X}$ or $R$ factors exceeding 3-sigma limits during the month. 
Thus, trends are revealed in the crystallographic orientation characteristics of Savannah River Plant fuel slugs. Future work will relate orientation characteristics to reactor behavior... Study of Mark V-B data should provide test slugs of widely varying history and permit further correlation between crystallographic orientation and behavior.

\section{Discussion}

SOURCE MATERIAL

The two suppliers of canned Mark VII-A fuel slugs are the Sylvania Nuclear Corporation (SCNC) and the hot press (HP) bonding facility at the Savannah River Plant. The Savannah River Plant X-Ray Diffraction Laboratory began routine surveillance of SCNC slugs in April 1961 and of HP slugs in May 1961. Surveillance prior to these dates is not included here because of a different heat treatment then in use, Data in this report are concerned solely with Mark VII-A salt-oil beta heat treated fuel slugs, produced under current manufacturing methods.

Slugs for routine surveillance:

SCNC: 5 slugs from each shipment received.

HP: $\quad$ I slug per day, taken at random from the production line.

\section{DIFFRACTION TECHNIQUES}

From each uranium slug, two samples are prepared for X-ray diffraction analysis. One sample is examined on a surface perpendicular to the slug axis (longitudinal); the second sample is examined on a radial surface of the slug (circumferential).

A Norelco X-Ray Diffractometer is used to gather information on the $020,110,021,002,111,112,131,023,200$ and 113 crystallographic planes. 
The Diffractometer is run at $1^{\circ}$ per minute scanning speed with a $1^{\circ}$ divergence slit, a 0.006 inch wide scatter slit, and a $1^{\circ}$ receiving slit. A copper target $X$-ray tube, operated at $40 \mathrm{kv}$ and $40 \mathrm{ma}$, is used as the source. A nickel filter confines the beam to copper K-alpha radiation. The integrated intensities are gathered by a Geiger tube.

Basic data collected by the Diffractometer is converted into a Texture Coeffictent for each of the 10 planes by the following relationship:

$$
T C_{1}=\frac{I_{1} / I_{01}}{\left(\frac{1}{10}\right) \sum_{i=1}^{10}\left(I_{1} / I_{01}\right)}
$$

where $\quad \mathrm{TC}_{1}=$ Texture Coefficient

$$
\begin{aligned}
& I_{1}=\text { Net Peak Intensity (excluding background) } \\
& I_{01}=\text { Random Intensities for Uranium }{ }^{3}
\end{aligned}
$$

An Area Welght Growth Index (G3) for the 10-plane case is also calculated. The formula 1s:

$$
G 3=\frac{\sum_{i=1}^{10}(\text { Aw1 })\left(I_{1} / I_{01}\right)\left(\cos ^{2} \beta 1-\cos ^{2} \gamma 1\right)}{\sum_{i=1}^{10}(\text { Aw1 })\left(I_{1} / I_{01}\right)}
$$

where $\quad$ G3 = Area Weight Growth Index ${ }^{3}$

$$
\text { Awi = Area Weight Factor }{ }^{4}
$$

$\gamma 1$ and $\beta 1=$ Angles the 1 plane makes with the $\gamma$ and $\beta$ crystallographic axes, respectively.

\section{DATA ANALYSIS}

To analyze the Area Weight Growth Index (G3) of these production slugs, $\bar{X}$ (average) and $R$ (range) charts ${ }^{5}$ were constructed. $\bar{X}$ is the arithmetic mean of four sequential samples, and $R$ is the difference between the largest and smallest value in a group of four. 
Previous histograms of the data strongly indicated the possibility of an inherent statistical control operating within the production system. It was therefore anticipated that a quality control approach would allow variabilities in the system which exceeded 3 -sigma limits to be explained.

The first construction of the $\bar{X}$ and $R$ charts for G3 (calculated manually) did in fact indicate a noticeable difference in the HP slugs produced prior to May 1961 (see figure 1). A subsequent check indicated these prior slugs had been produced using a bronze-tin heat treatment rather than an oil-quench heat treatment.

With this indication of a system under statistical control, further exploration using the Texture Coefficient (TC) data was warranted. The mass of data available dictated that a computer be used for the analysis. A program for the IBM 1401 computer was prepared.

Use of a computer was logical because of the increased speed and timeliness, and because TC and G3 data, calculated for each sample diffracted, were already in a computer system. Therefore, for the further $\bar{X}$ and $R$ analysis, output from the TC and G3 computations was used; input required very little human preparation.

Several months were required for formulating and testing the programing package. Conversion of IBM 650 data, computed prior to March 1962, was necessary so that the data would be compatible with the current FORTRAN TC and G3 programs. The converted data and current data were used to check the IBM 1401 Autocoder program which calculates and plots $\bar{X}$ and $R$ information.

Computer running time for the $\overline{\mathrm{X}}$ and $\mathrm{R}$ program, including graph copies necessary for reporting, is less than one-half hour. An additional benefit derived from this program is the availability of an up-todate magnetic tape file of all X-ray preforred orientation data from which other reports and computations can easily be made. 
Growth Index Value

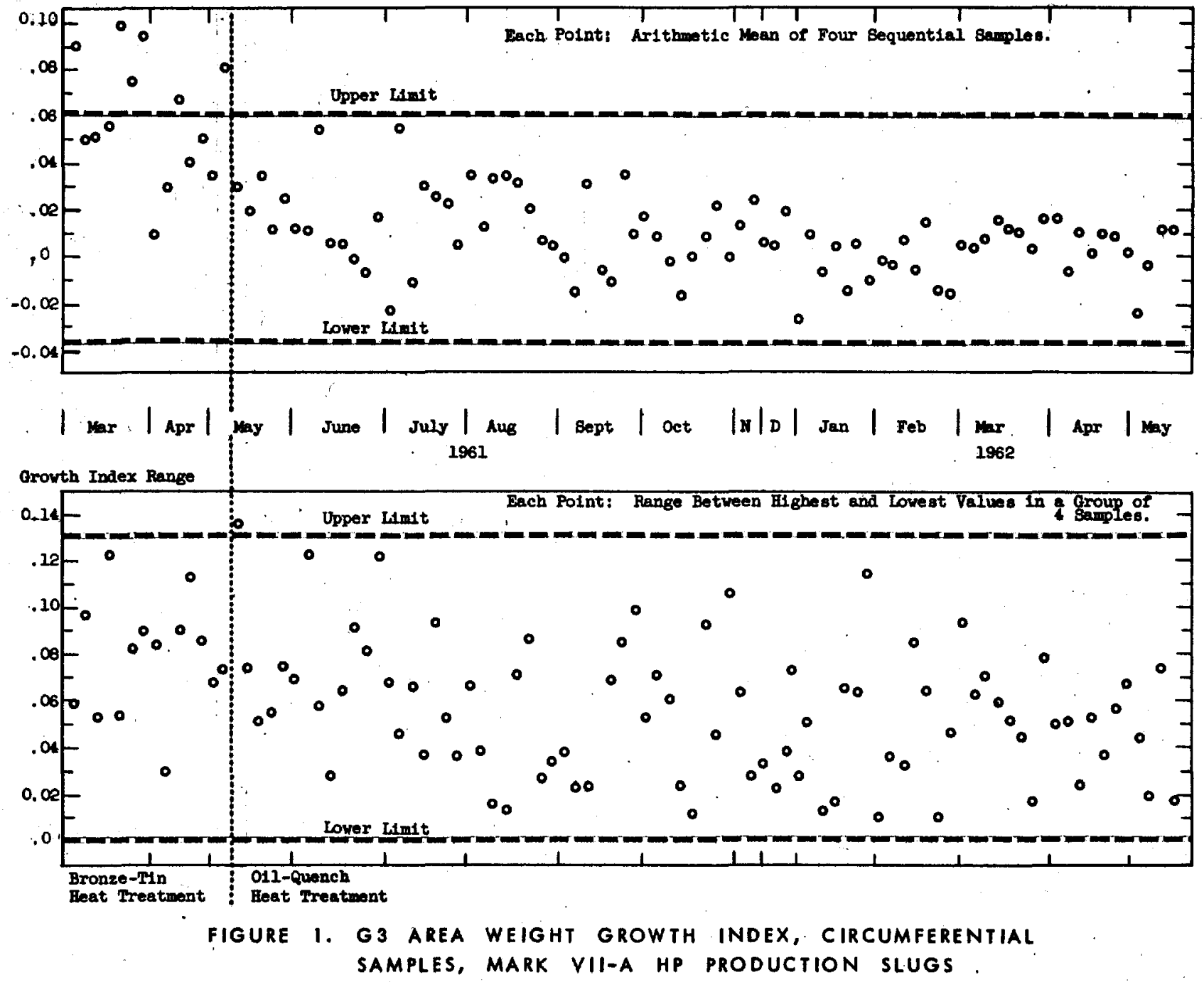


ANALYSIS OF COMPUTER OUTPUT

The system used to handle data from the X-ray diffractometer appears in figure 2. Data from the diffractometer is copied onto raw data sheets by a technician. Currently, one technician is diffracting between 250 and 300 samples per month, and in addition is handling the sample etching and the uranium inventory matters.

The raw data sheets are forwarded to a card punch group where information is punched into IBM cards. Four IBM cards are necessary for each raw data sheet. The cards are then fed into a computer where the following functions are performed:

(1) All raw data cards which were obviously out of sequence (the four raw data cards are numbered sequentially) are returned to be corrected.

(2) All raw data cards for samples whose TC's or G3 exceeded 3-sigma limits (determined by previous experience) are returned for checking, along with a finished data card containing the TC and $G 3$ values.

(3) Finished data cards (TC and G3) are returned for all other samples.

(4) Concurrent with the return of the finished data cards, a data listing is made.

A time delay is built into the computation system at this point so that $X$-ray laboratory personnel can check the data and correct it as necessary. When all samples which exceeded 3 -sigma limits have been checked, and necessary corrections have been made to raw data, the raw data cards that were returned during the first computer run are reprocessed along with finished data cards from the first computer run. The master magnetic tape file is then updated. Concurrent with the updating of the magnetic tape file, $\bar{X}$ and $R$ charts are computed and plotted by the computer. One complete set of $\bar{X}$ and $R$ charts is printed for laboratory use; an abbreviated set (the Exception Report) is printed along with its index for reporting purposes. These monthly Exception Reports contain only those charts which, since the last report, had either $\bar{X}$ or $R$ factors exceeding 3-sigma limits. 


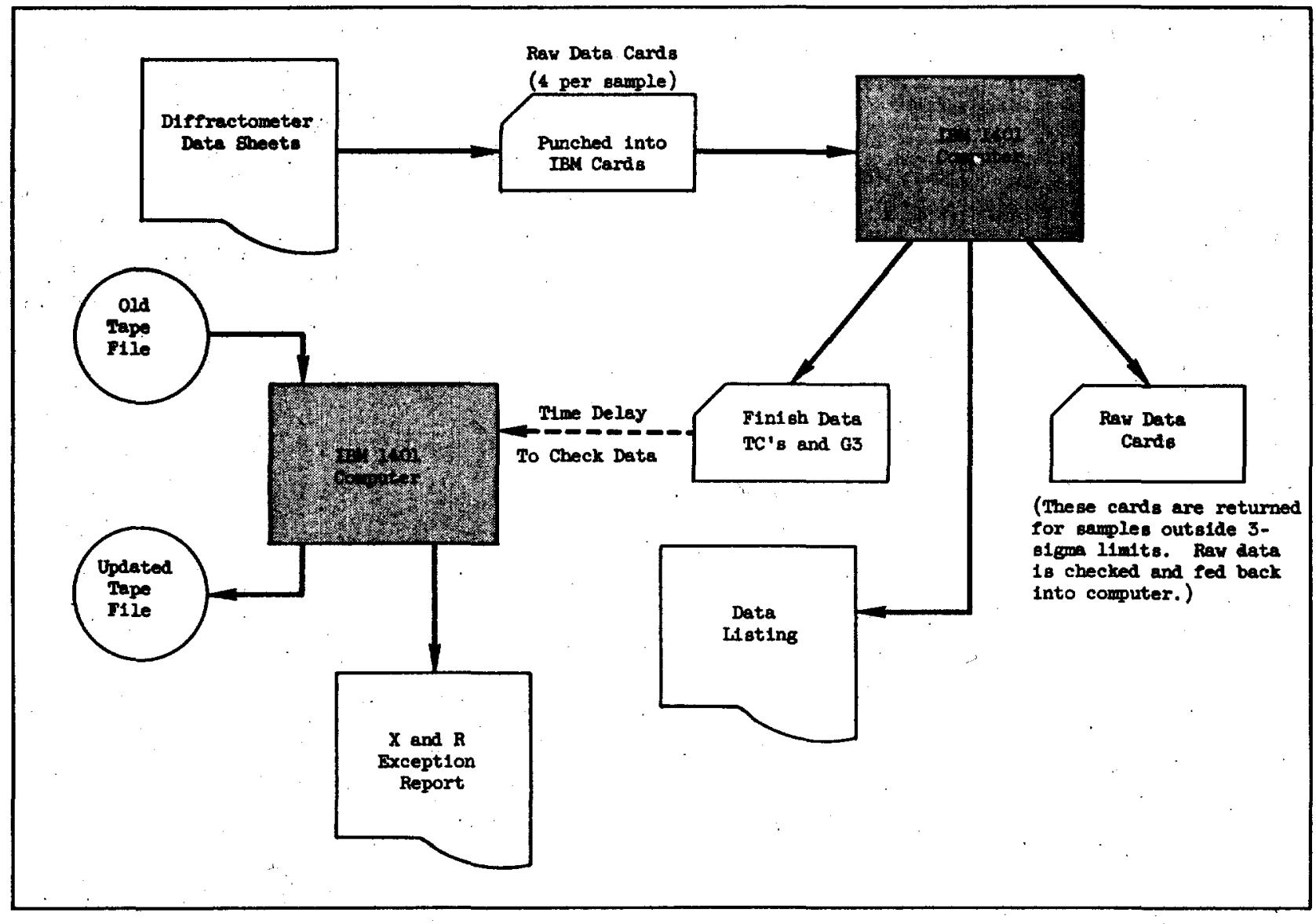

FIGURE 2. X-RAY DIFFRACTION DATA FLOW CHART 


\section{PERIODIC REPORTS}

The appendix contains charts that show the Savannah River Plant's $\bar{X}$ and $R$ experience through June 30, 1962. The charts show longitudinal and circumferential orientation data for Mark VII-A slugs of salt-oil beta heat-treated natural uranium. The charts represent $742 \mathrm{HP}$ and 734 SCNC samples.

Figure 3 is an example of an Exception Report index page.

Figure 4 is an example of the finished data used to calculate the $\bar{X}$ and $R$ charts. The X-ray laboratory has complete copies of all diffraction data discussed in this report and can make copies available to interested parties.

\section{References}

1. Sturcken, E. F., An X-Ray Method for Predicting the Stability of Natural Uranium at Low Burnup, DP-251, November 1957.

2. Permar, P. H., letter to Hood Worthington, Correlation of Anisotropic Growth of Unrestrained Uranium With Preferred Orientation By the Growth Index Concept. June 11, 1962.

3. Morris, P. R., ed, USAEC Report NLCO-804, National Lead Company, Cincinnati, Ohio.

4. Morris, P. R., ed, USAEC Report NLCO-764, National Lead Company, Cincinnati, Ohio.

5. Grant, E. L., Statistical Quality Control. New York, MeGraw-Hill Book Company, 1952. 


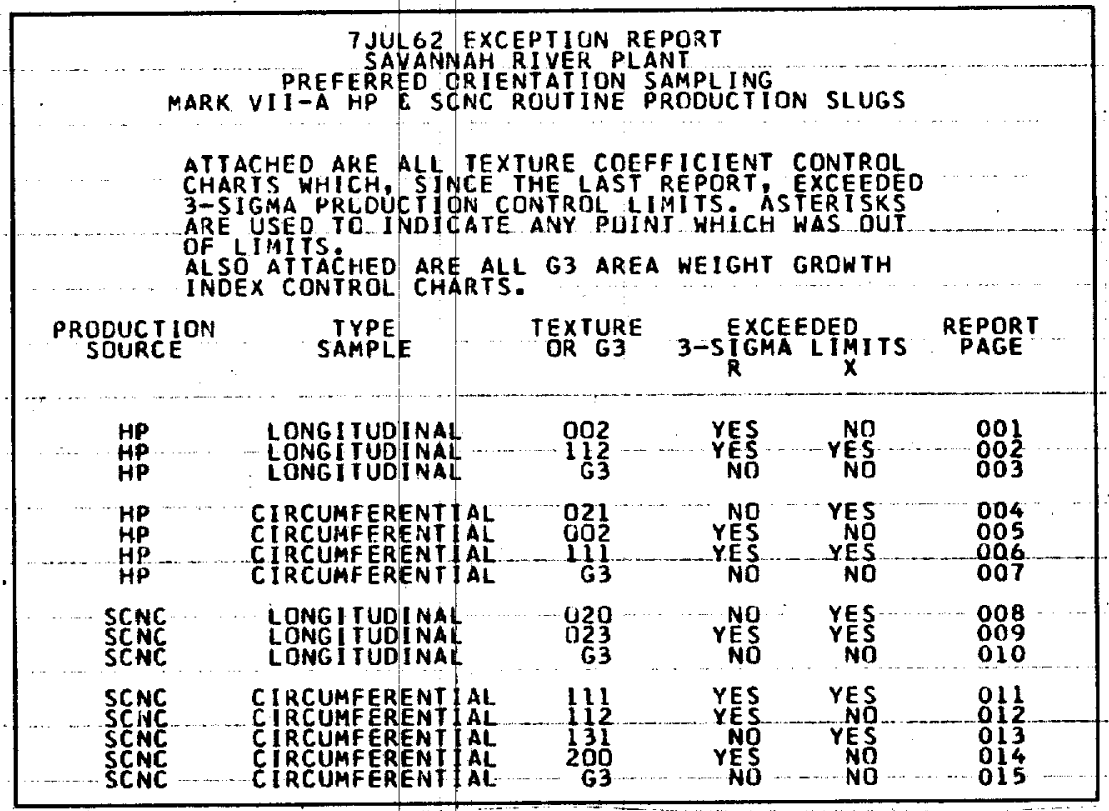

FIGURE 3. SAMPLE INDEX PAGE FROM AN EXCEPTION REPORT

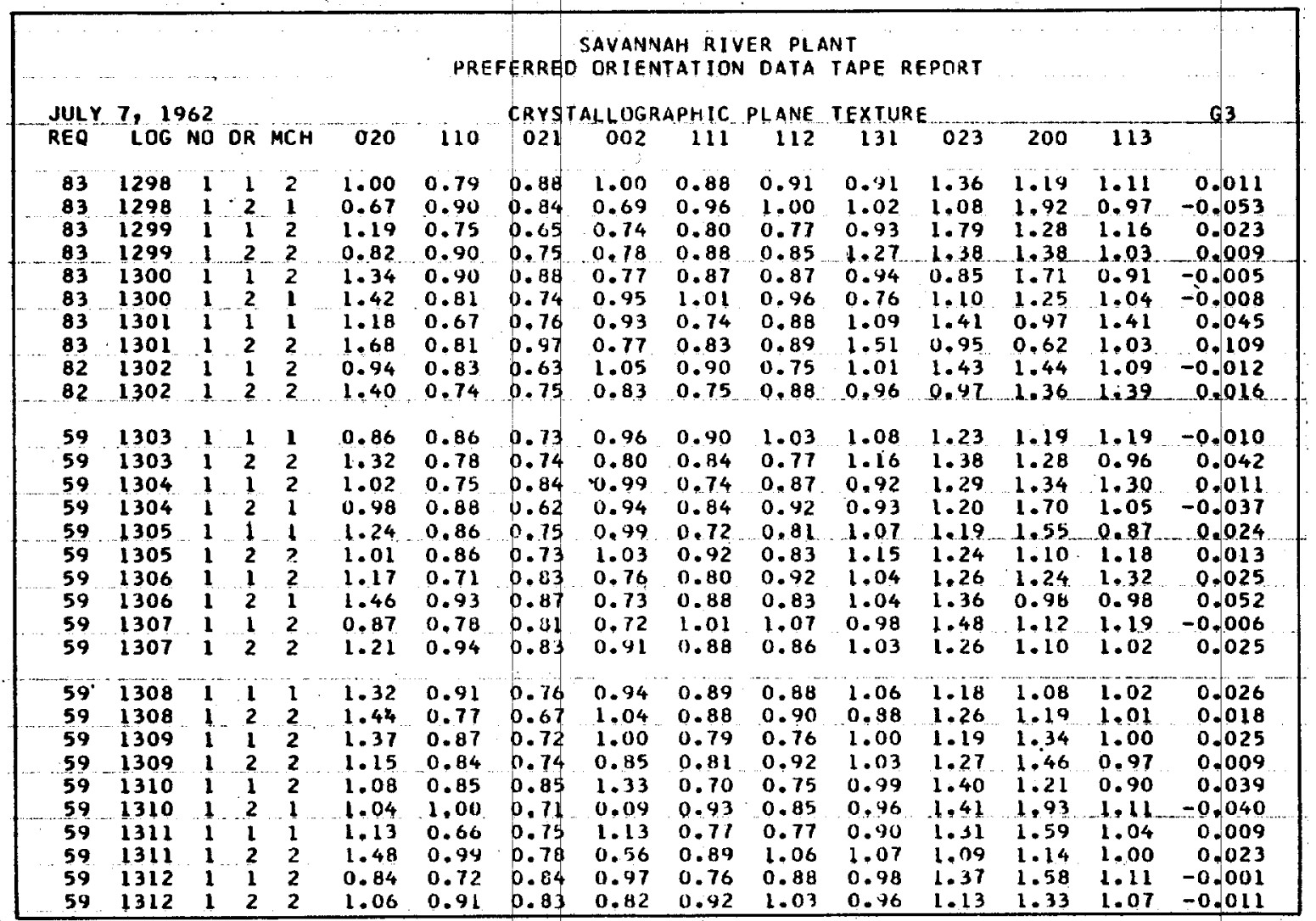

FIGURE 4. SAMPLE OF DATA USED TO CALCULATE $\bar{x}$ AND $R$ CHARTS.

The numbers below the crystallographic plane lextures refor to Miller plane indices.

G3. Areo weight growth index 


\section{Appendix}

\begin{tabular}{|c|c|c|}
\hline Title & & Page \\
\hline $\begin{array}{l}\text { Mark VII-A HP Routine Production S } \\
\text { Longitudinal Cut } \\
\text { Crystallographic Plane Texture }\end{array}$ & $\begin{array}{l}\text { gs } \\
020 \\
110 \\
021 \\
002 \\
111 \\
112 \\
131 \\
023 \\
200 \\
113 \\
\text { G3 }\end{array}$ & $\begin{array}{l}12 \\
13 \\
14 \\
15 \\
16 \\
17 \\
18 \\
19 \\
20 \\
21 \\
22\end{array}$ \\
\hline $\begin{array}{l}\text { Circumferential Cut } \\
\text { Crystallographic Plane Texture }\end{array}$ & $\begin{array}{r}020 \\
110 \\
021 \\
002 \\
111 \\
112 \\
131 \\
023 \\
200 \\
113 \\
\text { G3 }\end{array}$ & $\begin{array}{l}23 \\
24 \\
25 \\
26 \\
27 \\
28 \\
29 \\
30 \\
31 \\
32 \\
33\end{array}$ \\
\hline
\end{tabular}




\section{Appendix}

Title

Mark VII-A SCNC Routine Slugs

Longitudinal Cut

Crystallographic Plane Texture
$020 \quad 34$

$110 \quad 35$

$021 \quad 36$

$002 \quad 37$

$111 \quad 38$

$112 \quad 39$

13140

$023 \quad 41$

$200 \quad 42$

$113 \quad 43$

G3 44

Circumferential Cut

Crystallographic Plane Texture $\quad 020 \quad 45$

$110 \quad 46$

$021 \quad 47$

$002 \quad 48$

$111 \quad 49$

11250

$131 \quad 51$

$023 \quad 52$

$200 \quad 53$

$113 \quad 54$

G3 55 


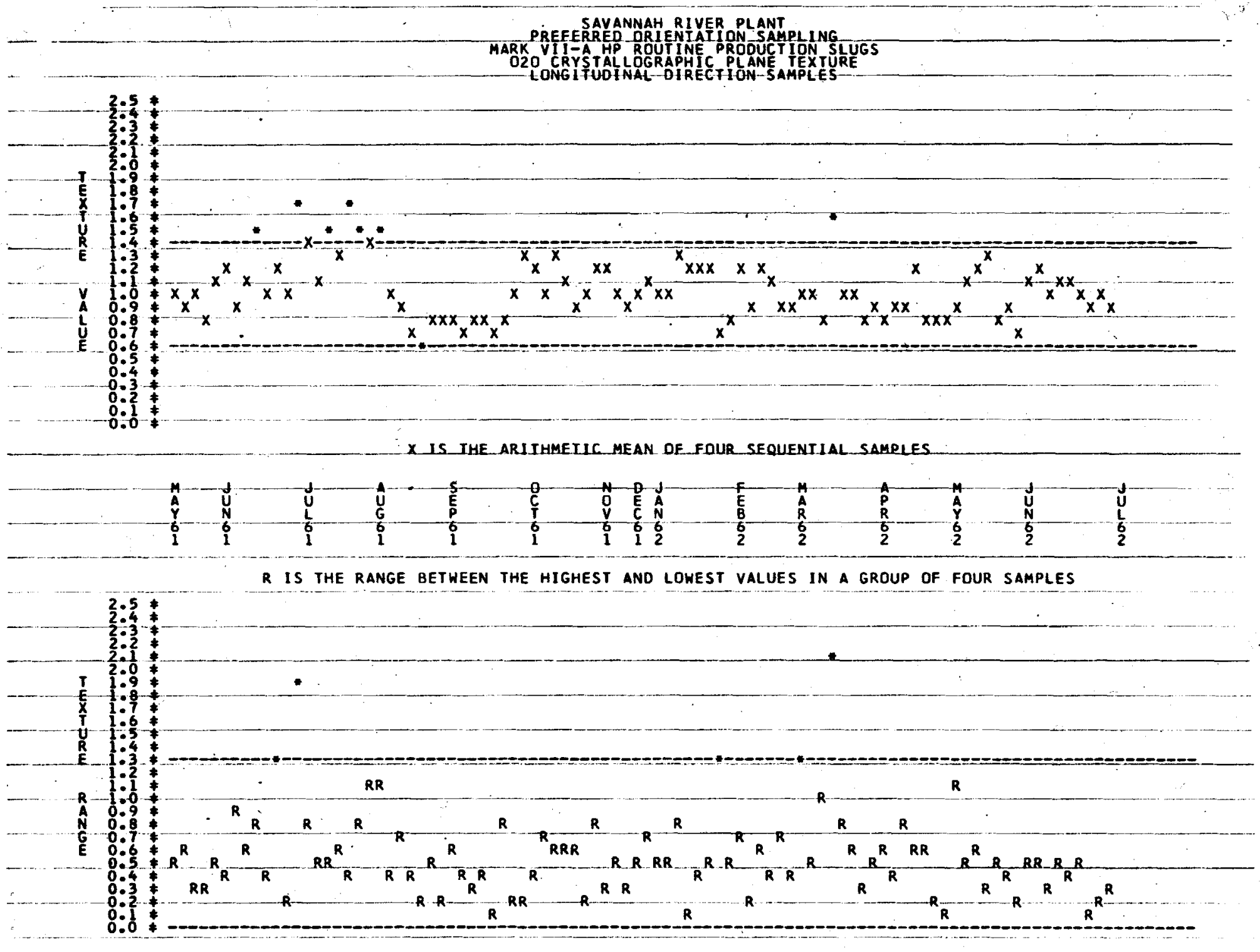



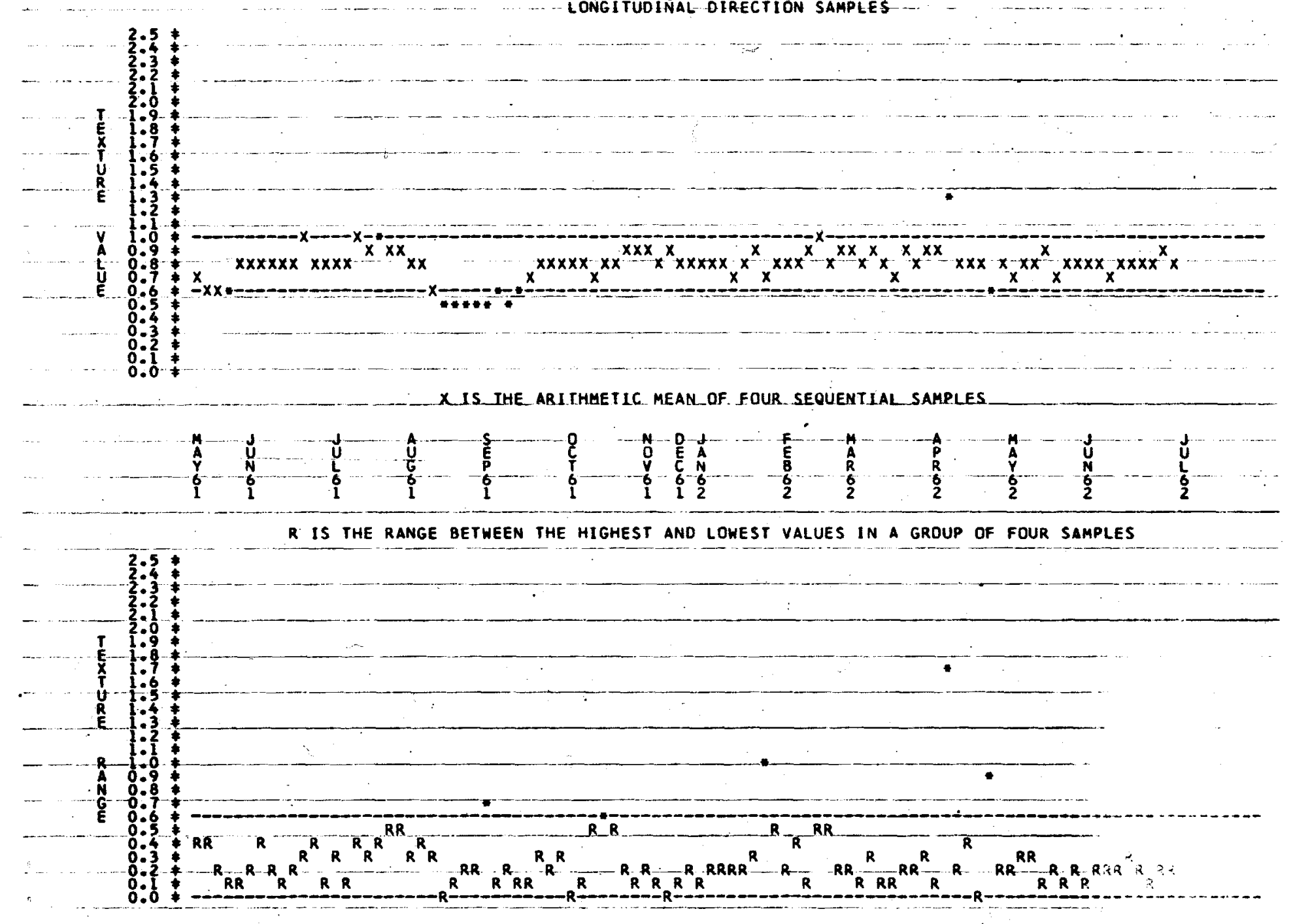

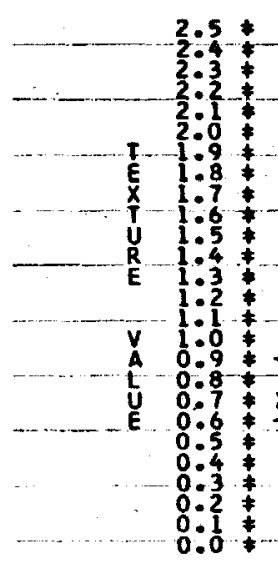

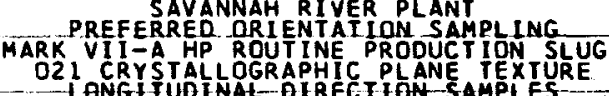

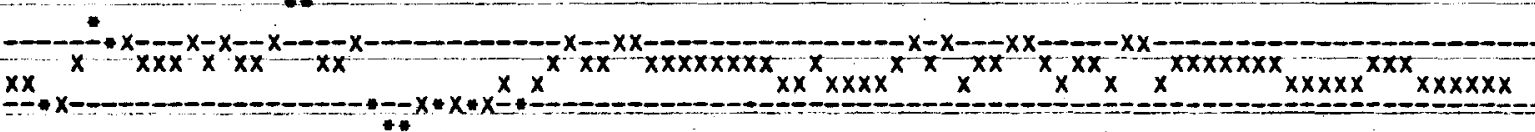

$X$ IS THE ARITHMETIC MEAN OF FOUR SEQUENTIAL SAMPLES

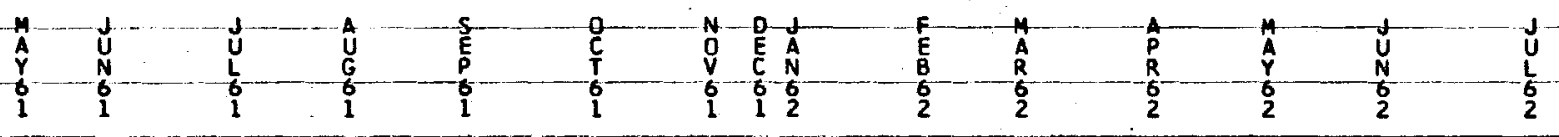

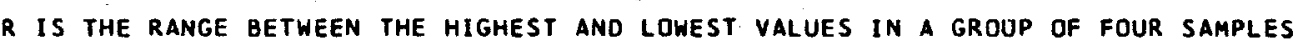

2.5
$2: 4$
$2: 3$
$2: 2$
$2: 1$
$2: 0$
$1: 9$
$1: 8$
$1: 9$
$1: 6$
$1: 5$
$1: 4$
$1: 2$
$1: 1$
$1: 0$
$0: 9$
$0: 8$
$0: 7$
$0: 6$
0.5
$0: 4$
$0: 2$
$0: 1$
0.0

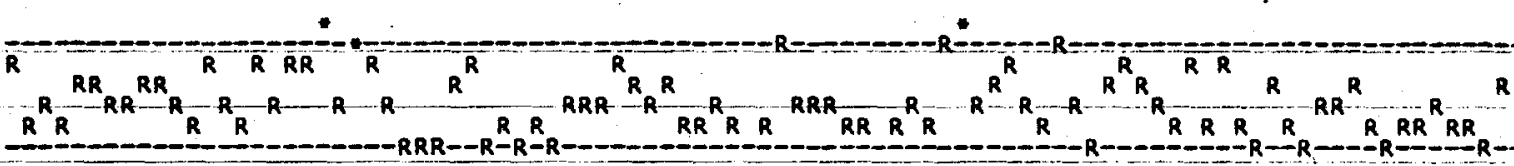




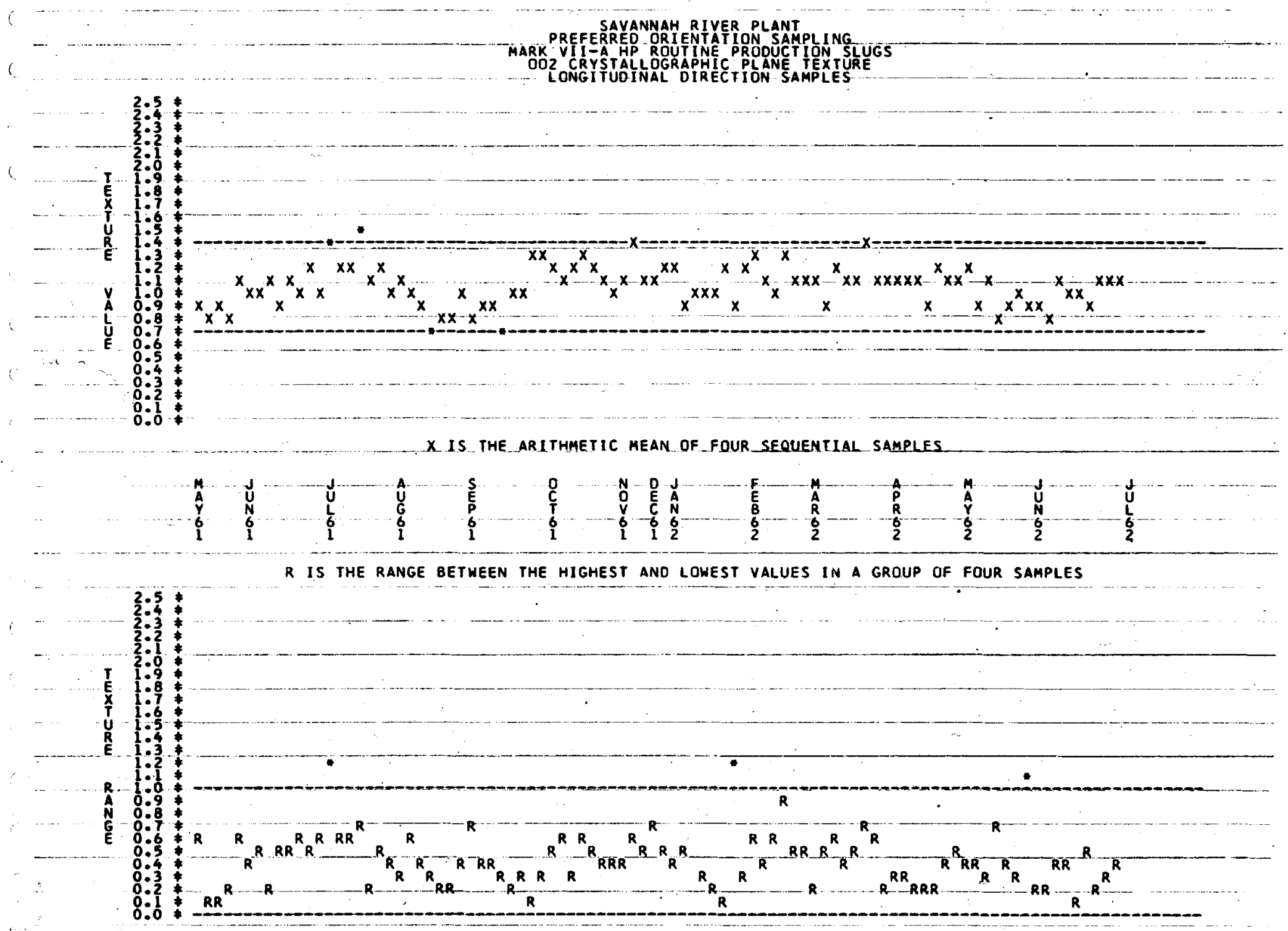




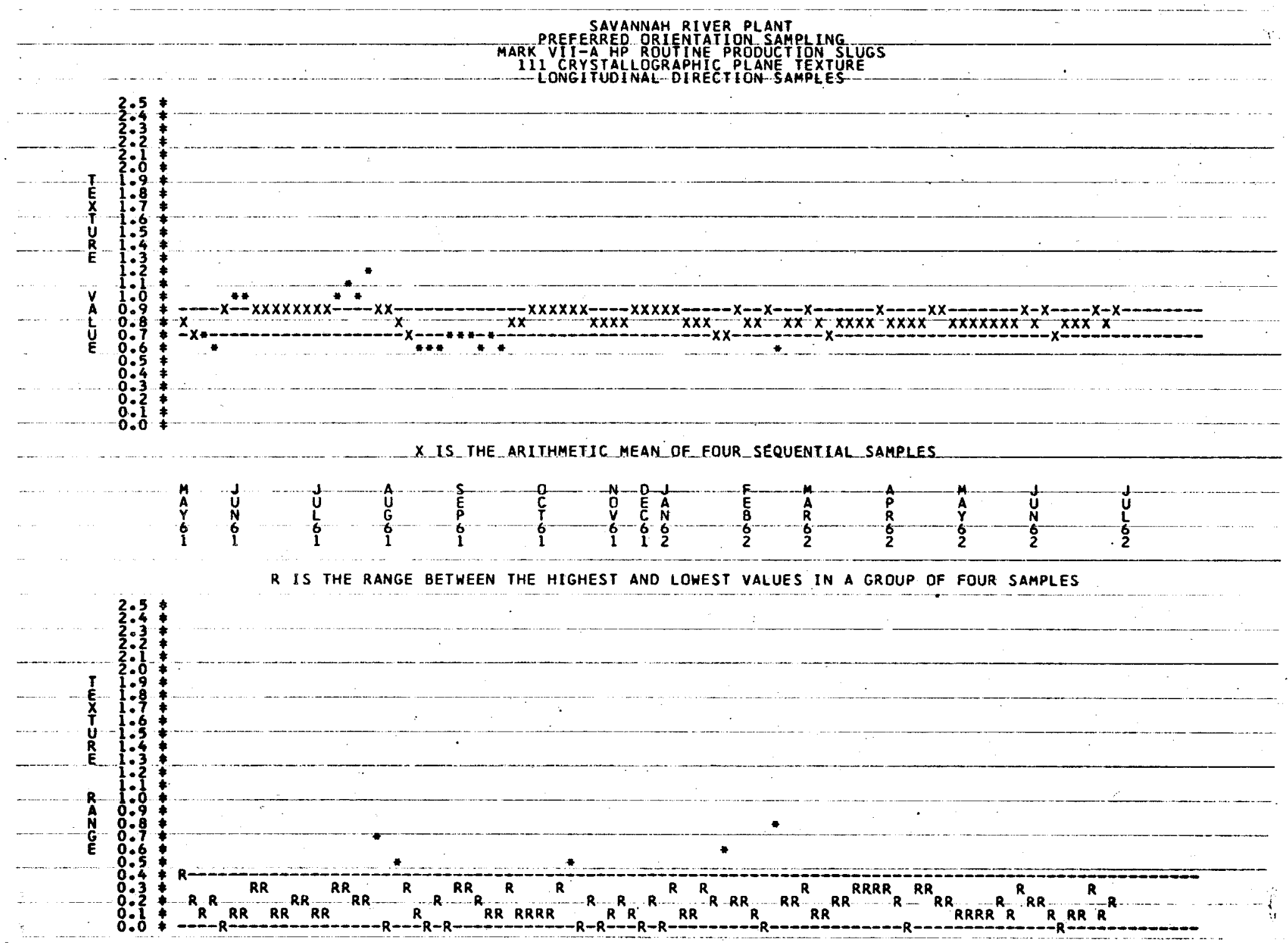




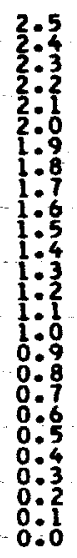

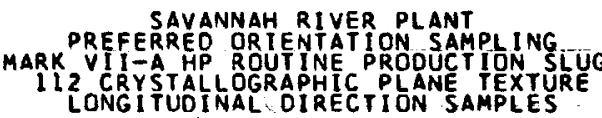

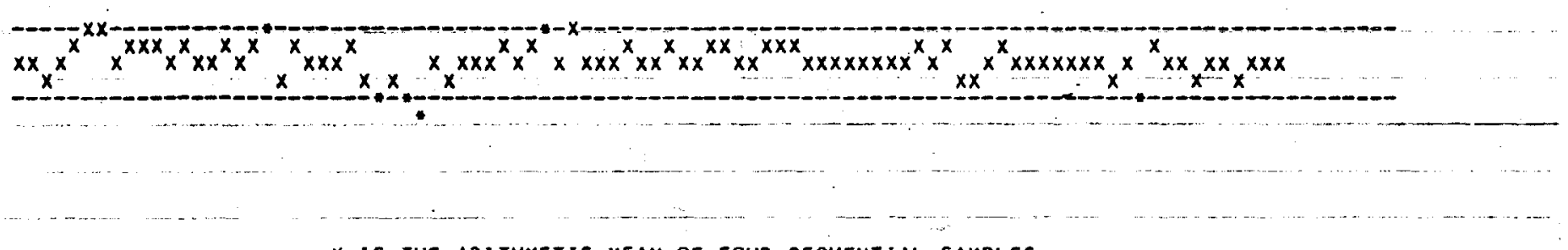

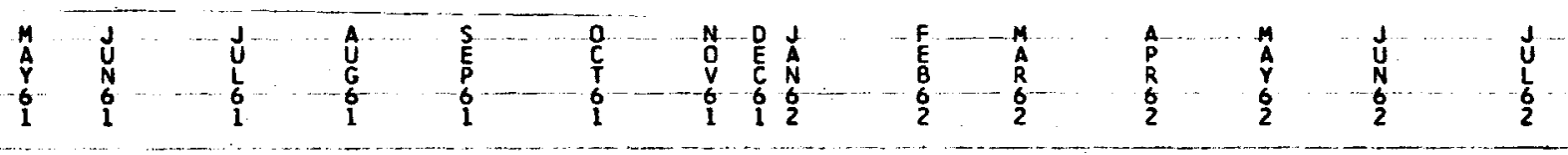

$R$ is THE RANGE BETWEeN THE HIGHEST ANO LOWEST VALUES IN A GROUP OF FOUR SAMPLES

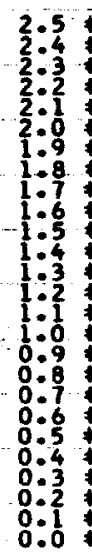

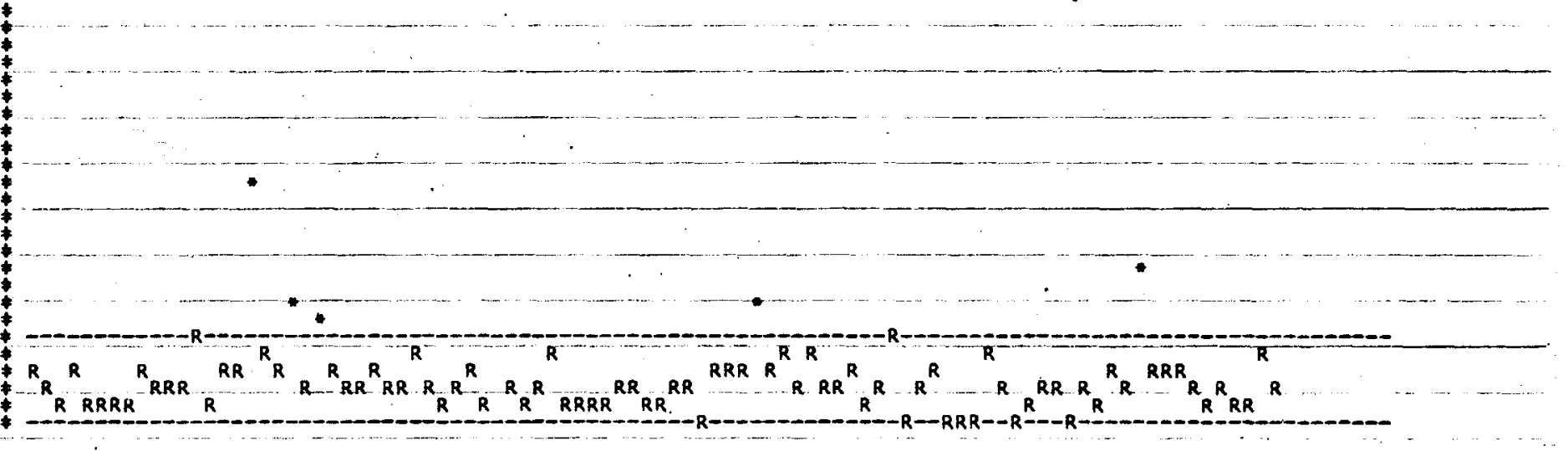

$\leftleftarrows$ 


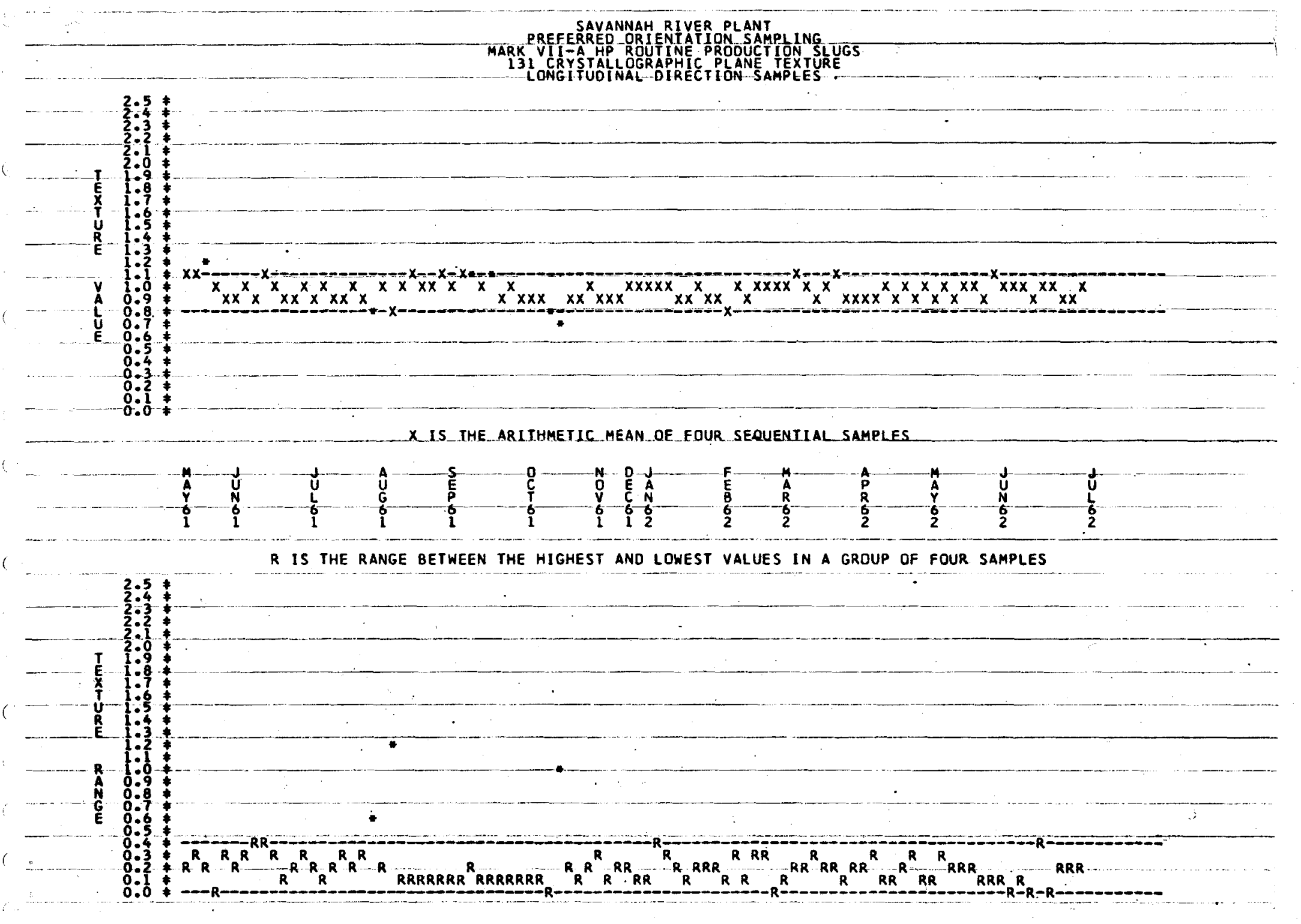




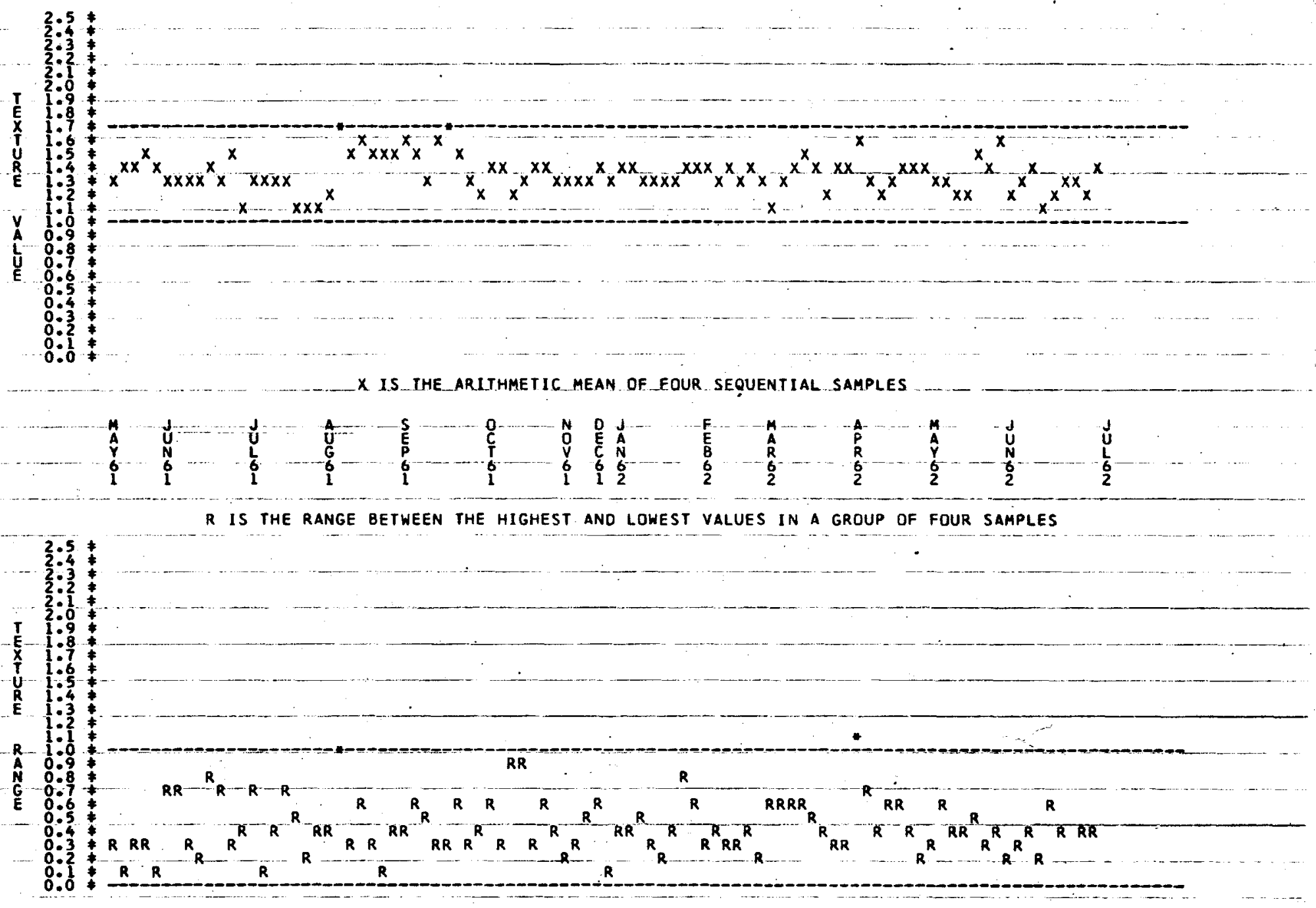





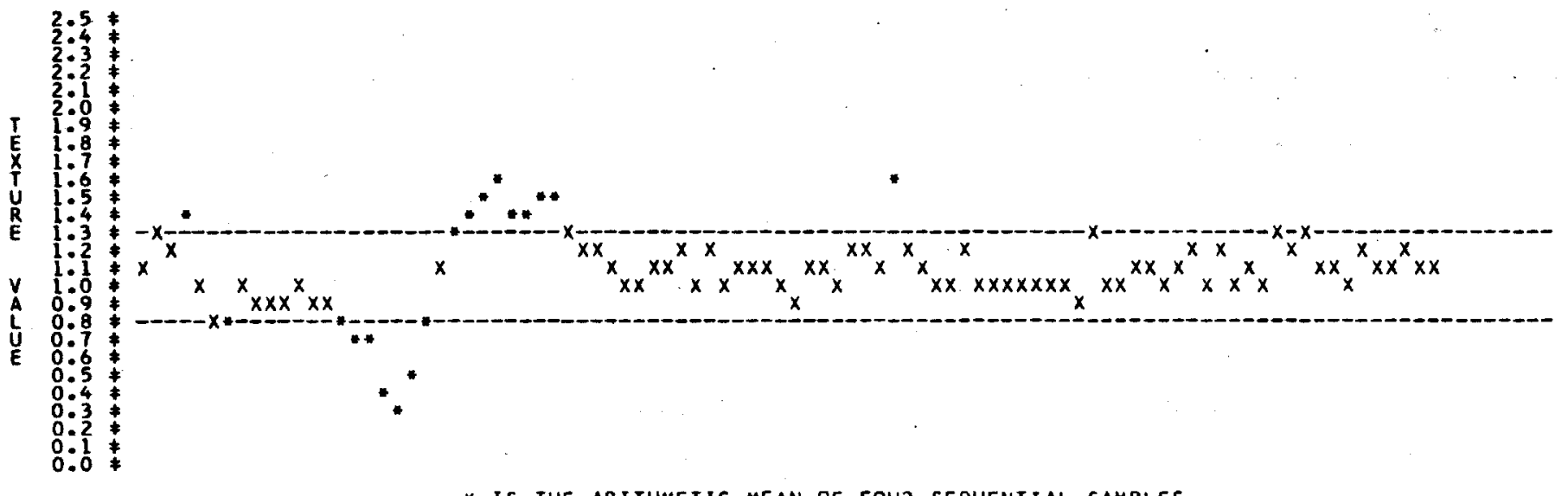

$x$ Is the arithmetic mean of four sequential. Samples

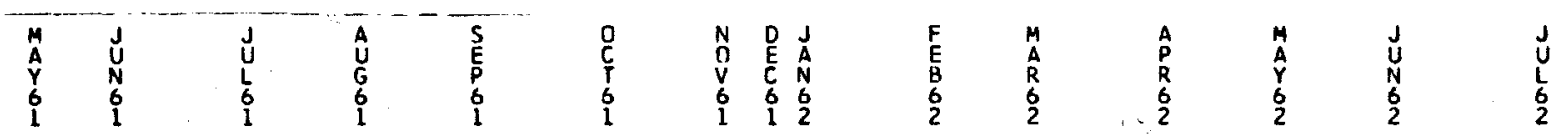

R is the range betheen the highest and lowest values in a group of four samples

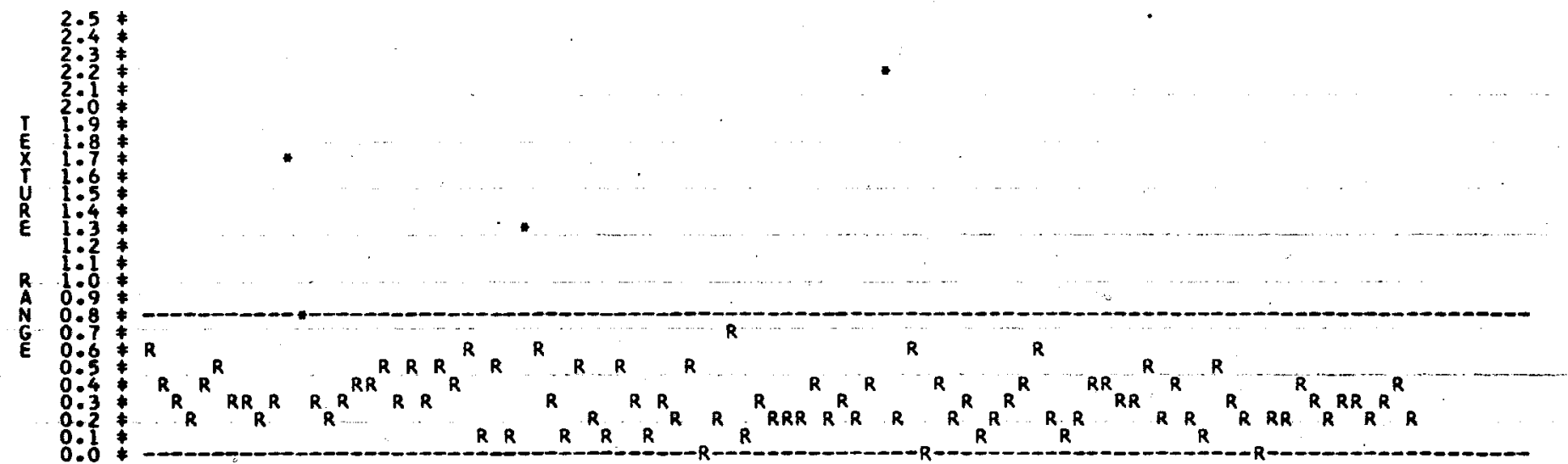


PREFERAVANNAH RIVER PLANT

MARK VII-A HP ROUTINE PRODUCTIDN SLUGS

LONGITUDINAL DIRECTION SAMPLES

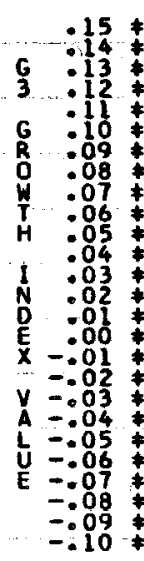

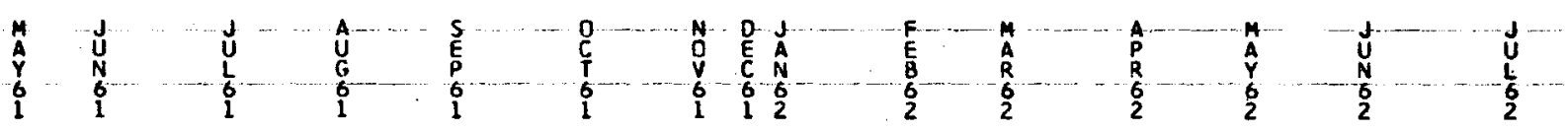

R IS THE Range between the highest and lowest Values in a group of four samples

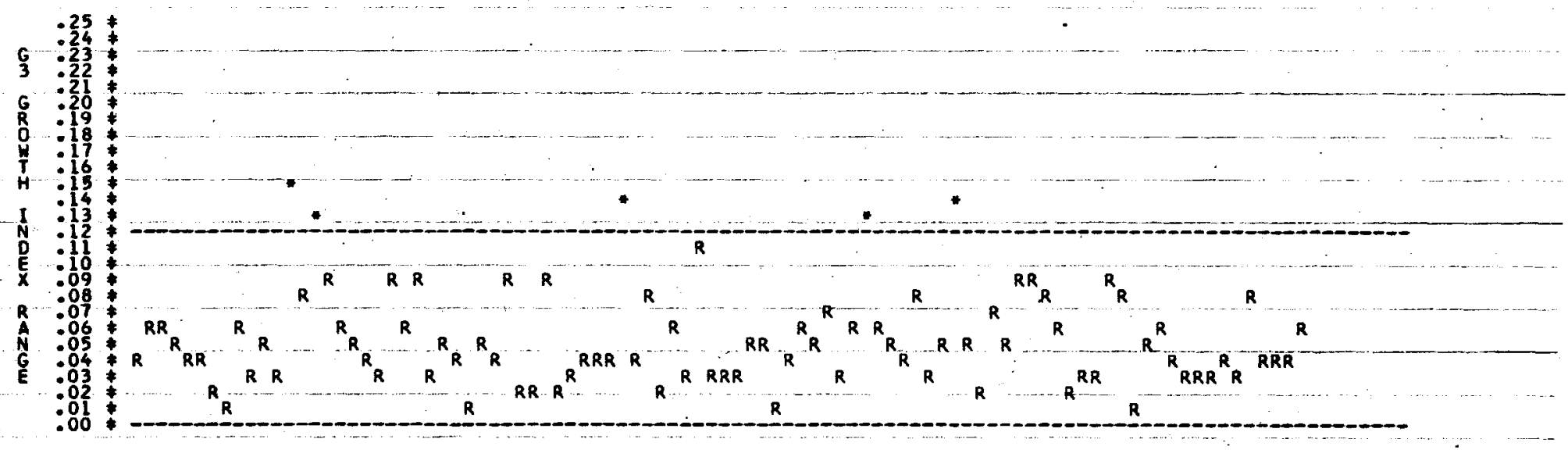


SAYANNAH RIVER PLANT
PREFERRED ORIENTATION SAMPLING

MARK VII-A HP ROUTINE PRDDUCTIION SLUGS

OZO CRYSTALLOGRAPHIC PLANE TEXTURE

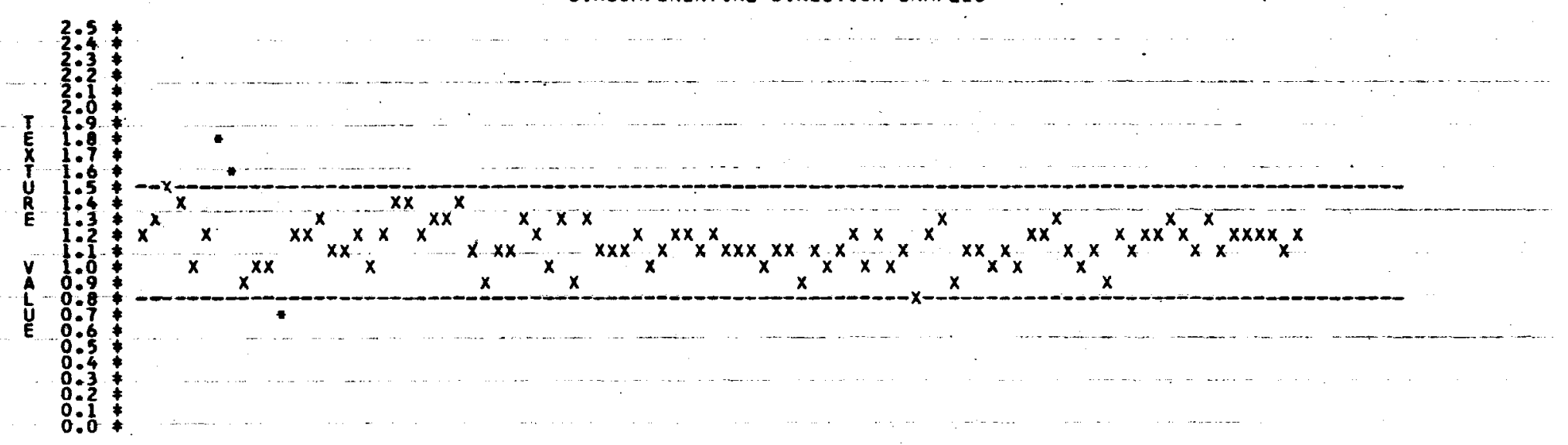

$x$ IS. THE ARITHMETIC MEAN OF FOUR SEQUENTIAL SAMPLES

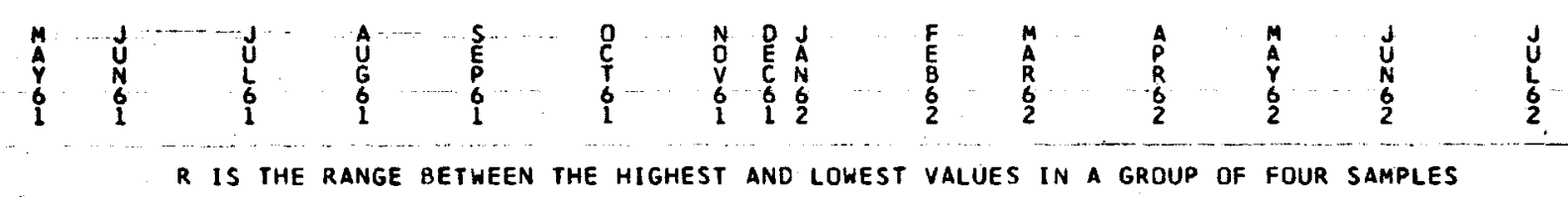

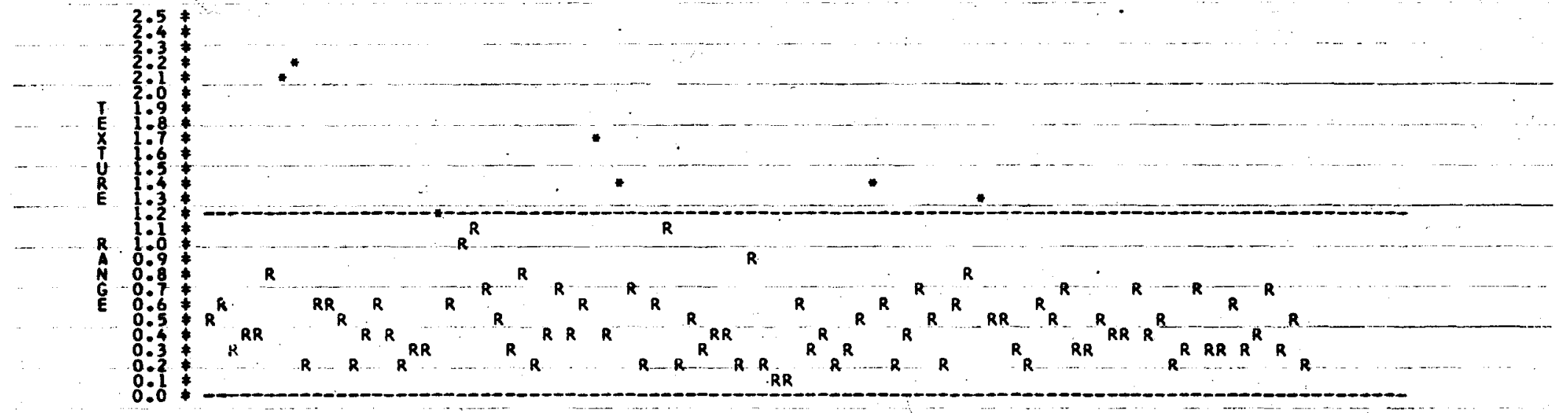




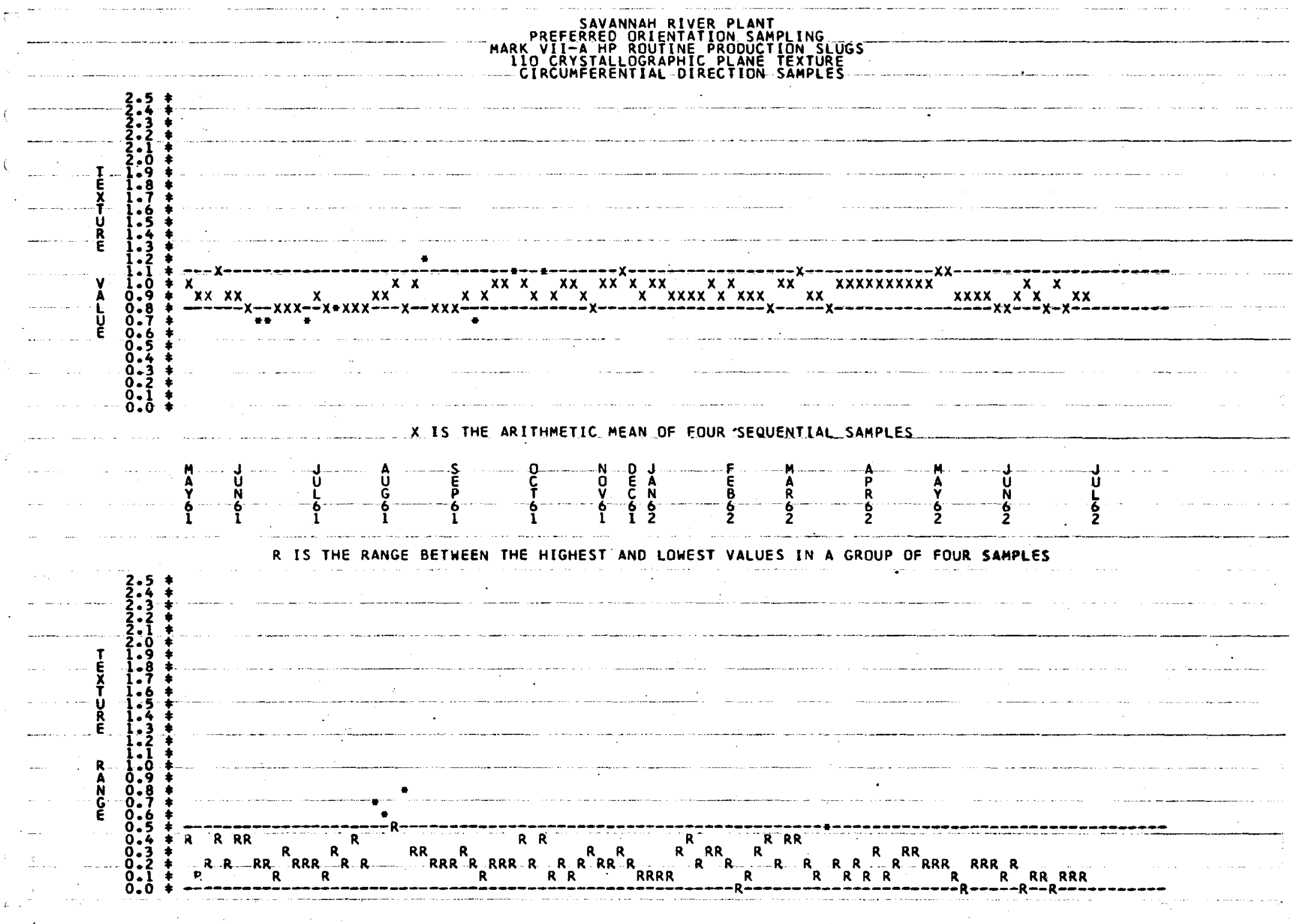





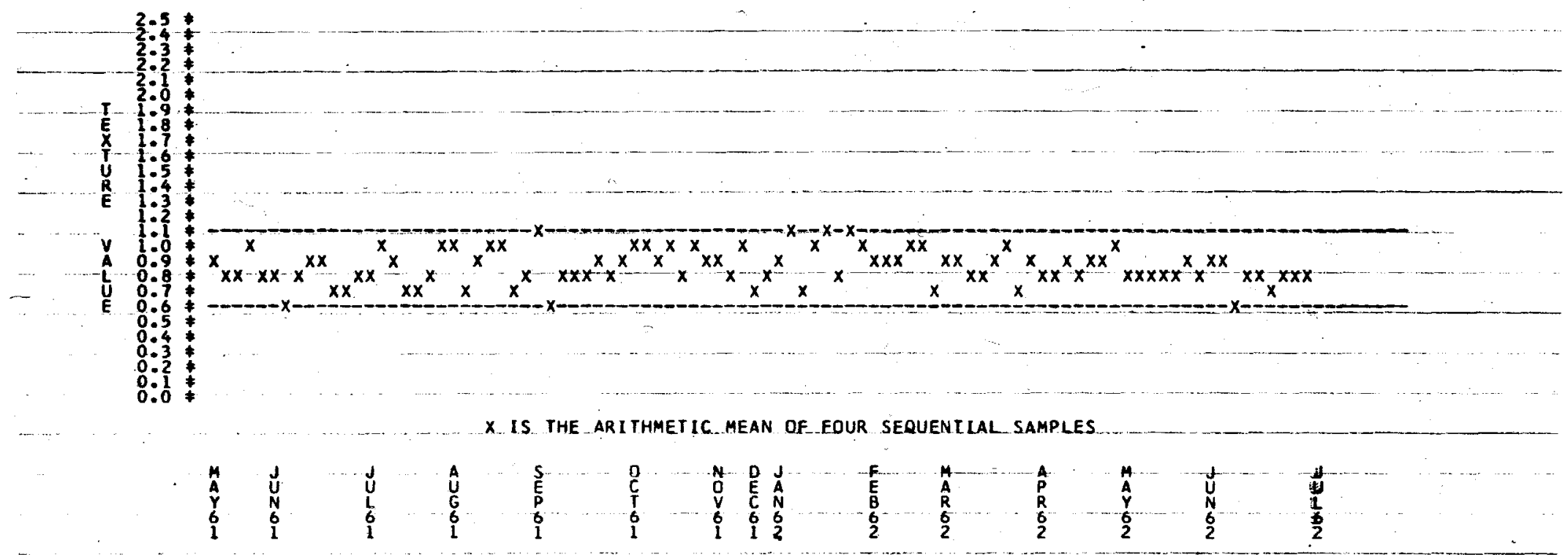

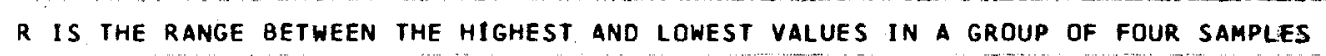

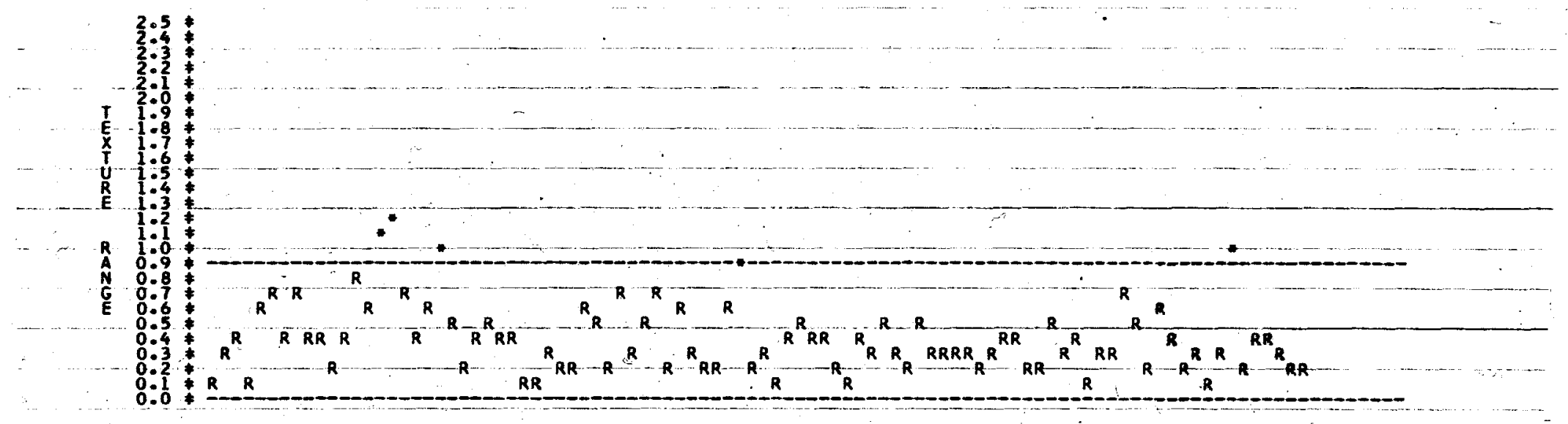




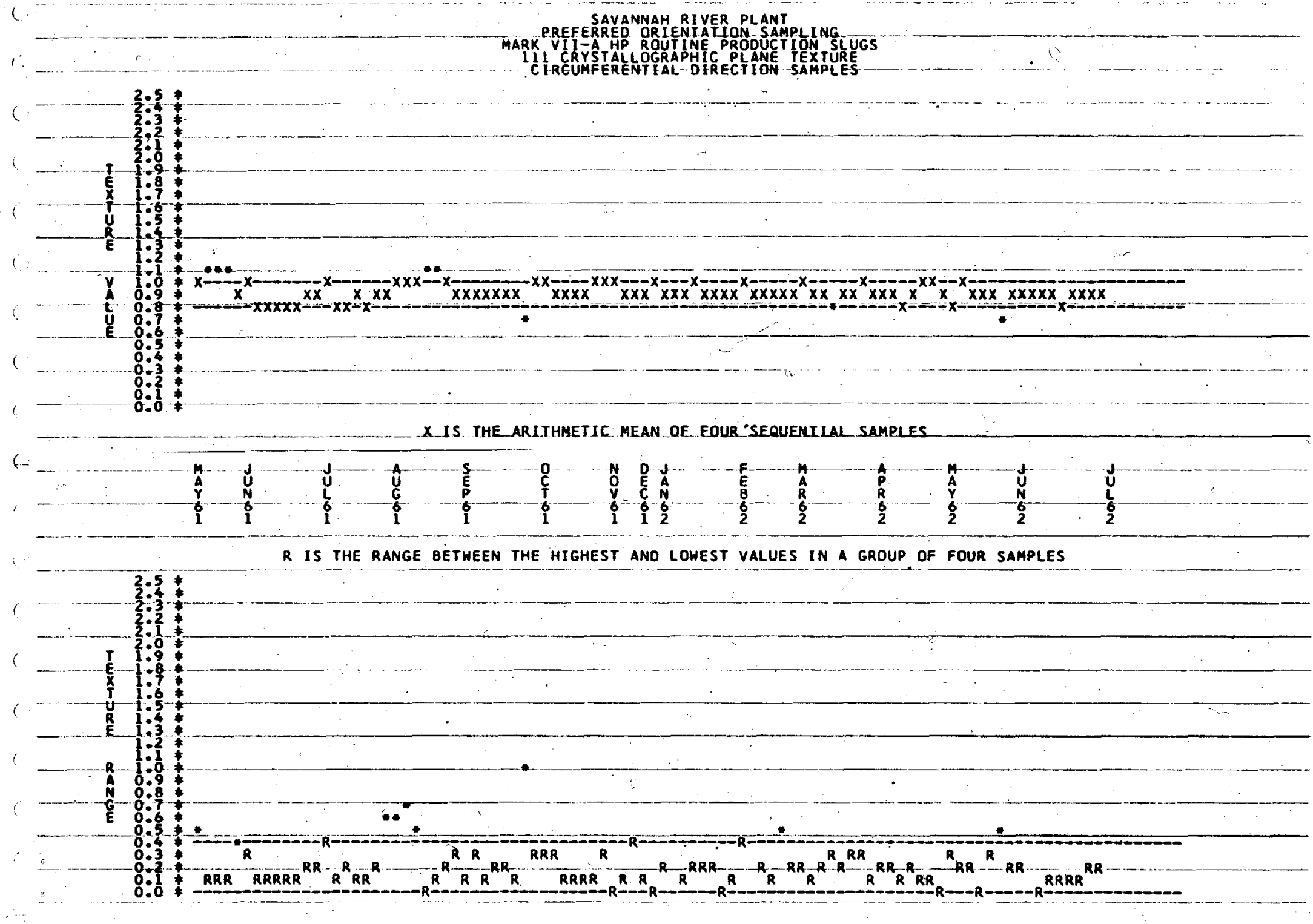




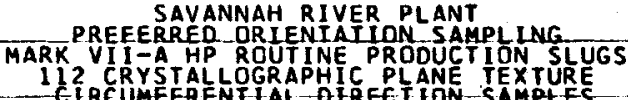

$\approx$

:

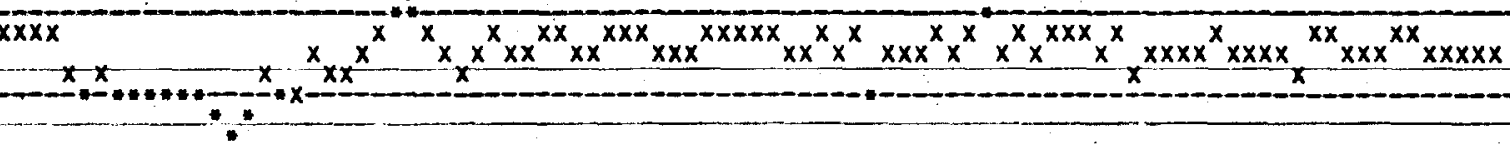

$X$ IS THE AR LTHMETIC MEAN OE EQUR SEQUENTHAL SAMPLES

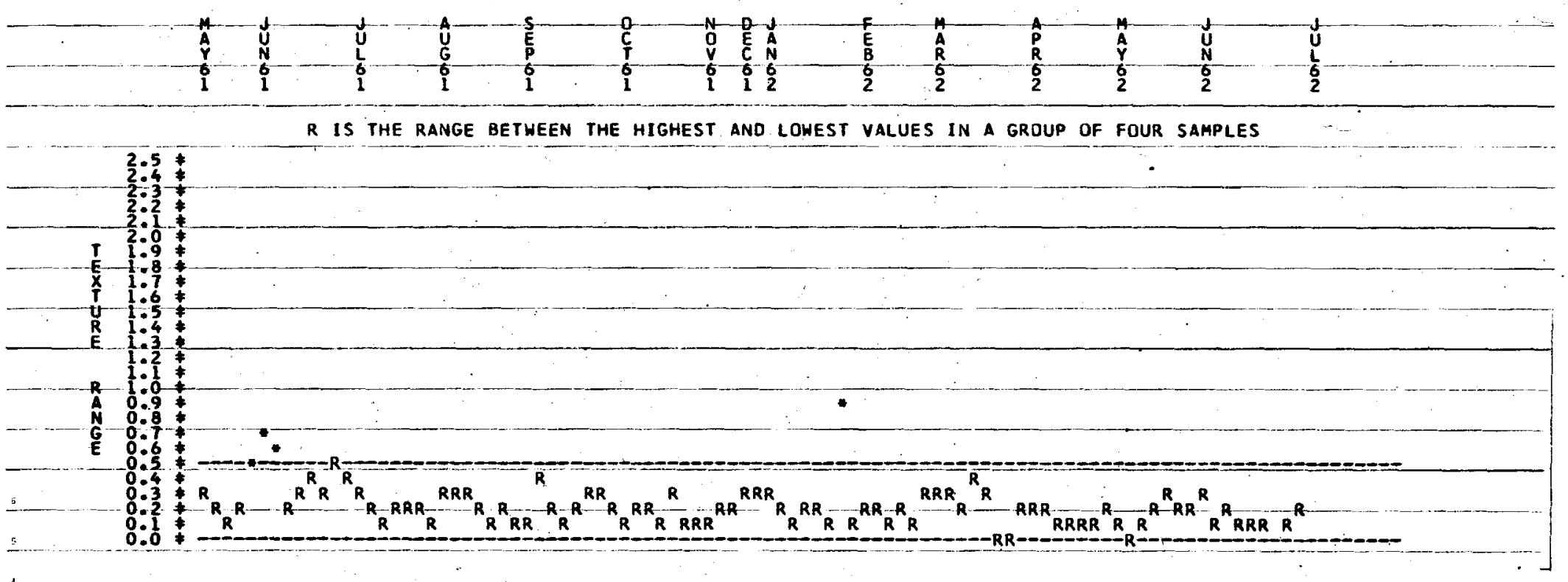




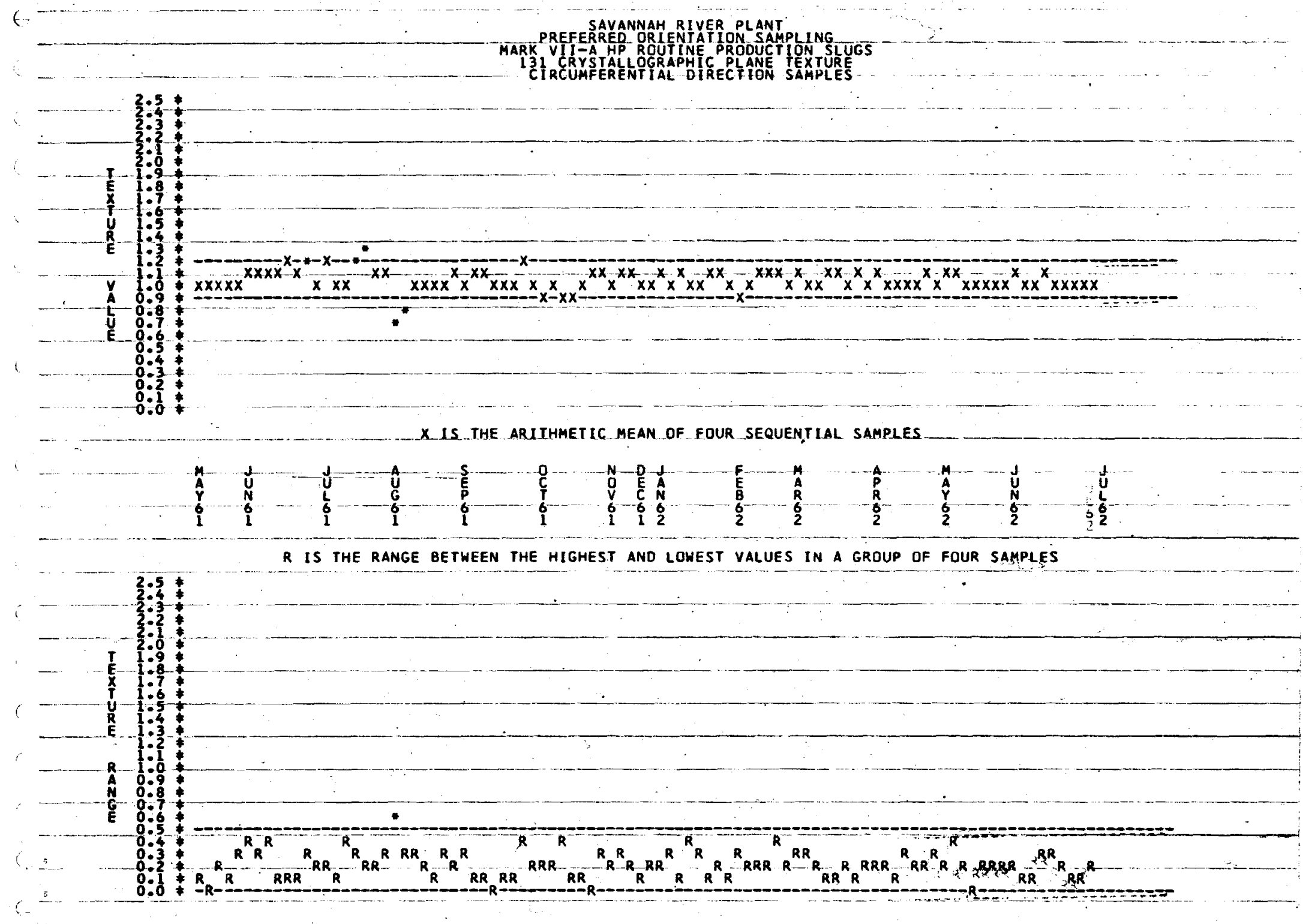


$--\frac{x-1}{x \times x x^{2} x}$

${ }^{x} \times$

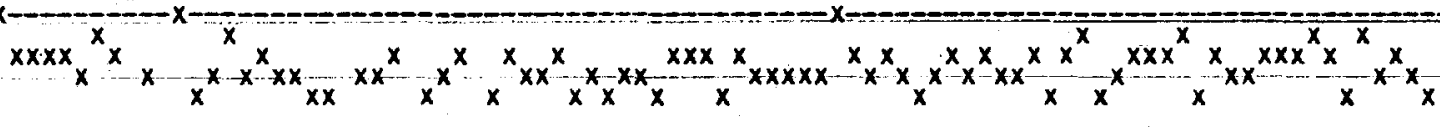

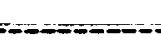

$X$ IS THE ARLIHMETIC MEAN OF FOUR SEQUENTLAL SAMPLES

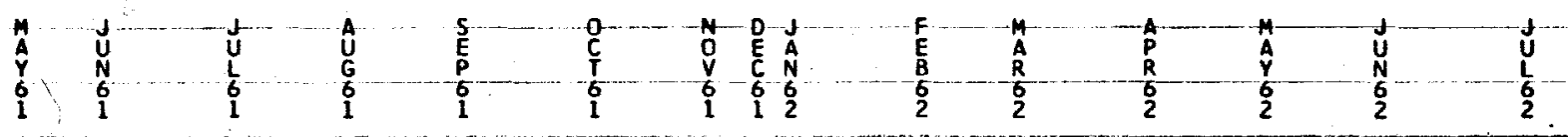

$R$ IS THE RANGe BeTWEen THE HIGHEST AND LOWEST VALUES IN A GROUP OF FOUR SAMPLES

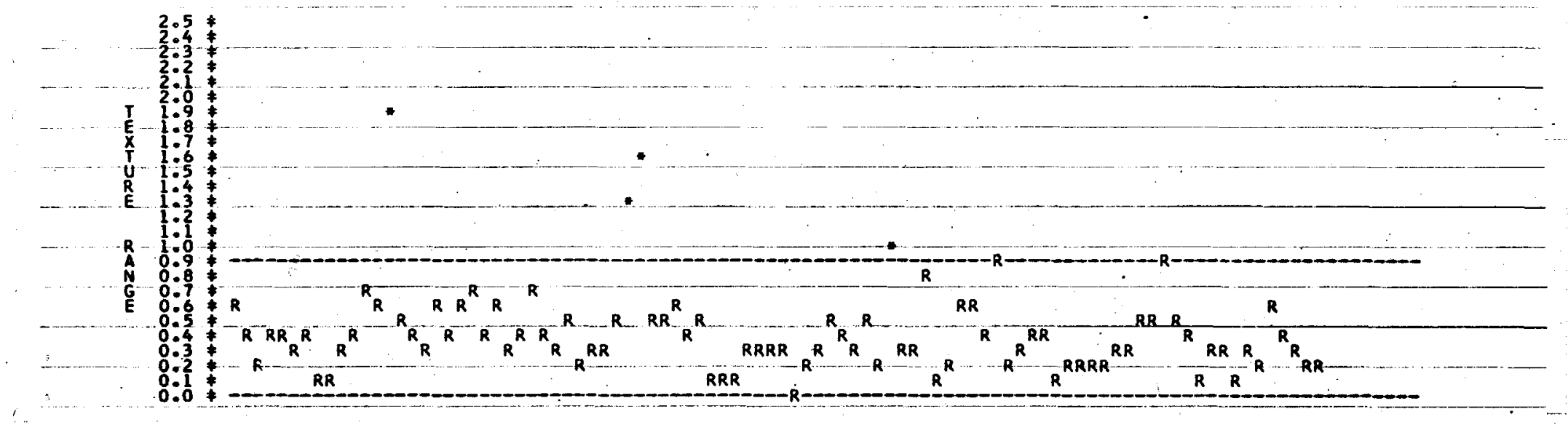




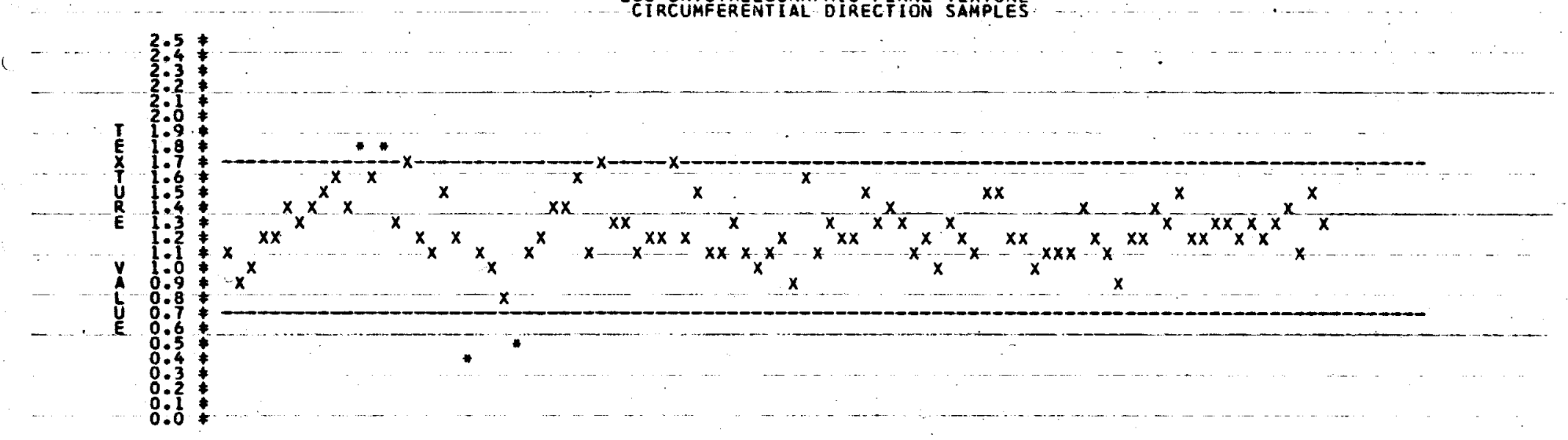

$X$ is the arithmetic mean of four seQuent lal samples.

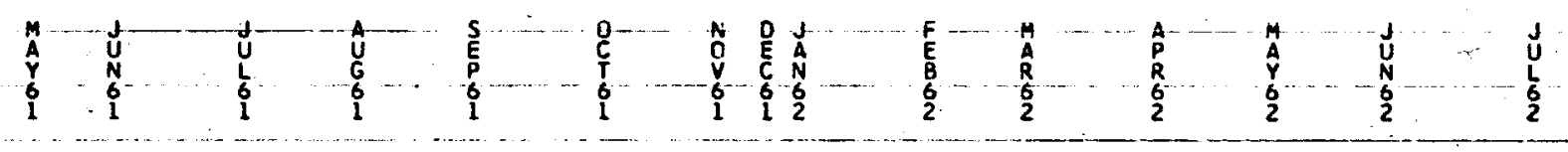

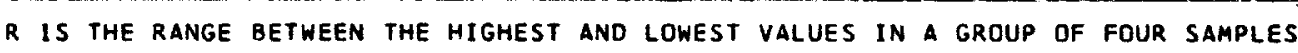

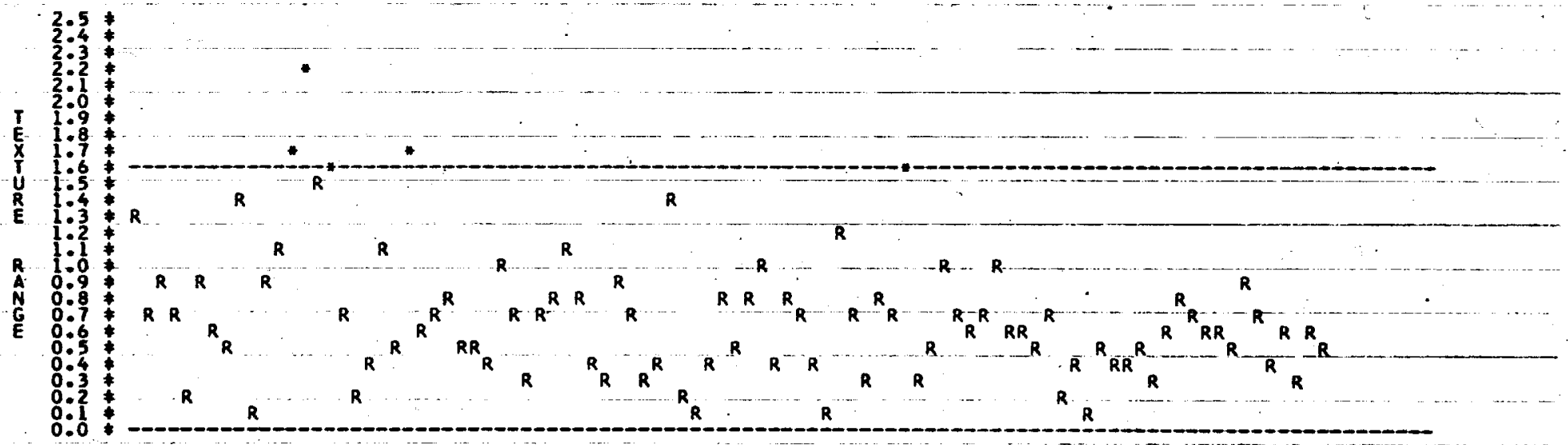




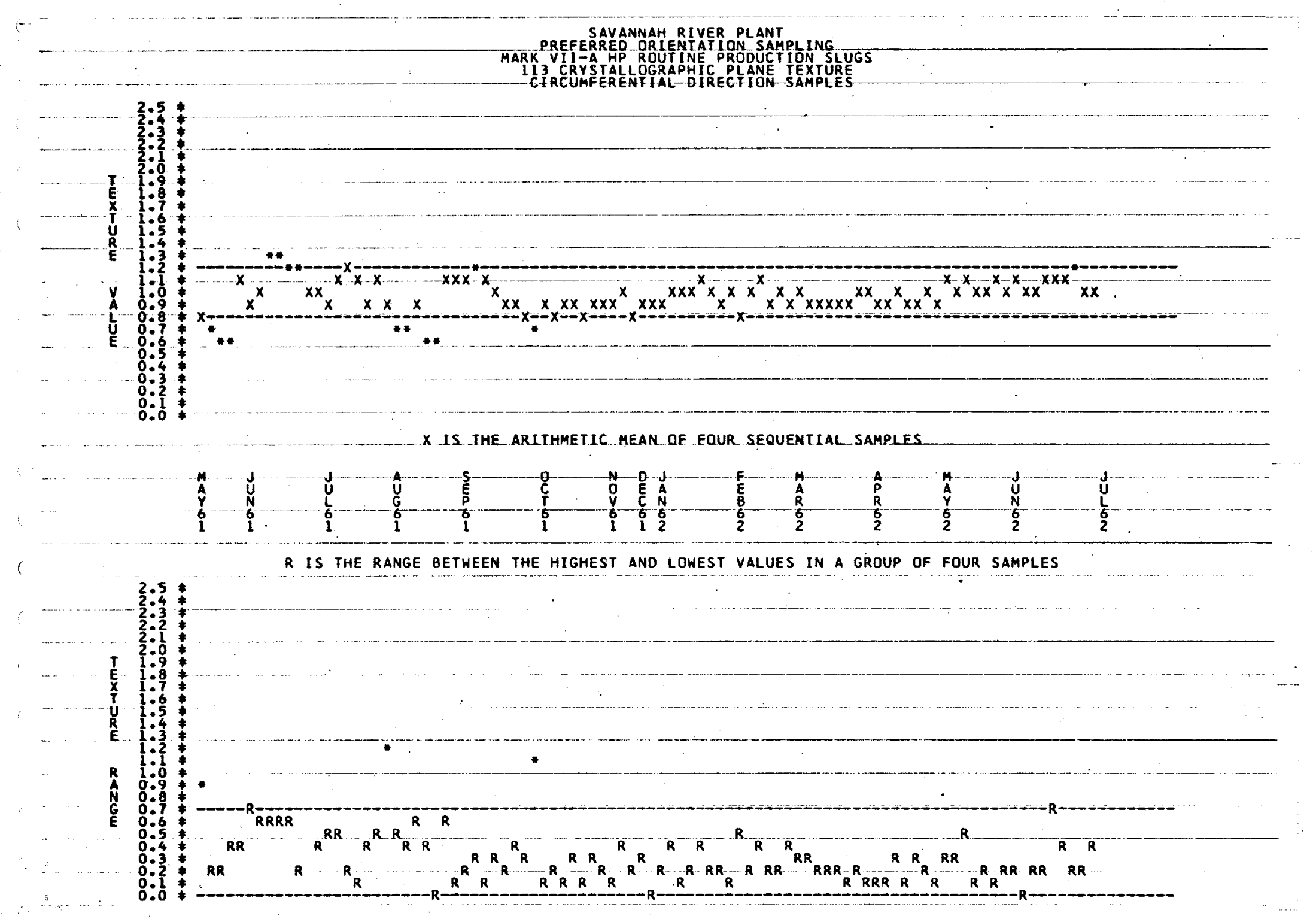




\section{PREFERAVANNAH RIVER PLANT}

MARK VII A HP ROUTINE PROOUCTION SLUGS

CIRCUMARERENTIAL DIRECTION SAMPLES

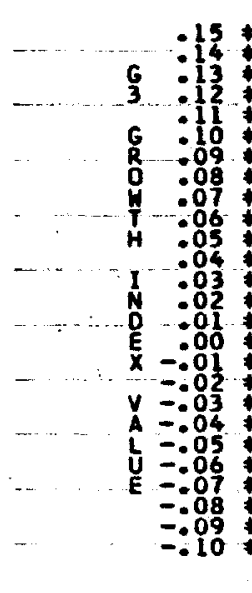

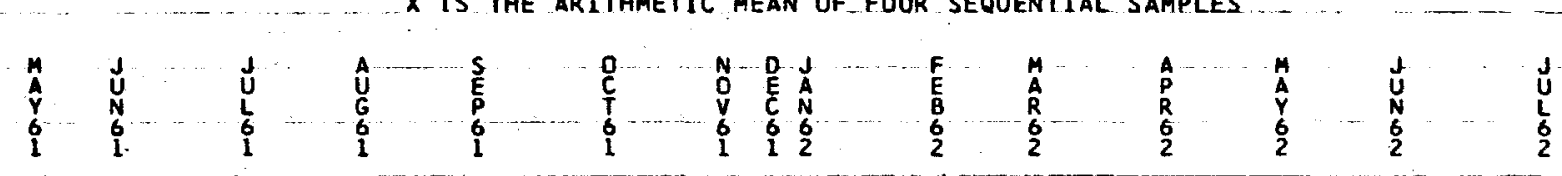

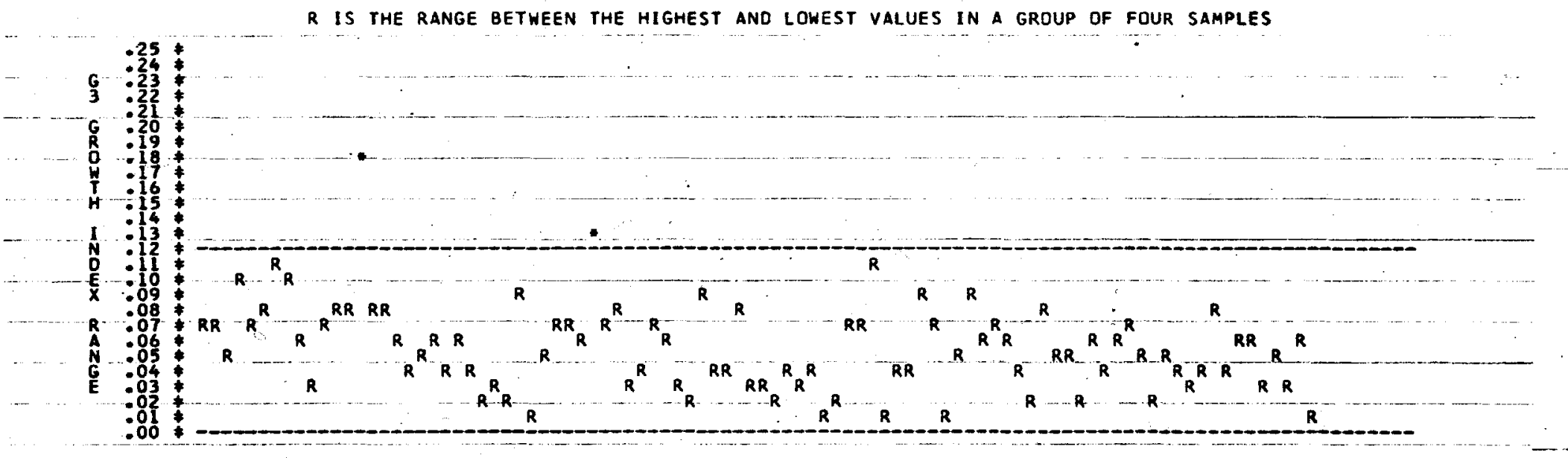


PREFERRED OR AH RIVER PLANT

MARK Y I - A SC NC ROUTINE PRODUCTION SLUGS
OEO CRYSTALLOGRAPHIC PLANE TEnURE

w

$X$ IS THE ARITHMETIC MEAN OF. FOUR SEQUENTIAL SAMPLES

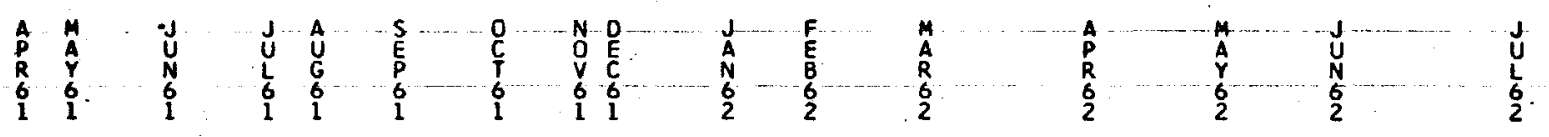

R IS THE RANGE BETHEEN THE hIGHEST aND LOWEST VALUES IN A GROUP OF. FOUR SAMPLES

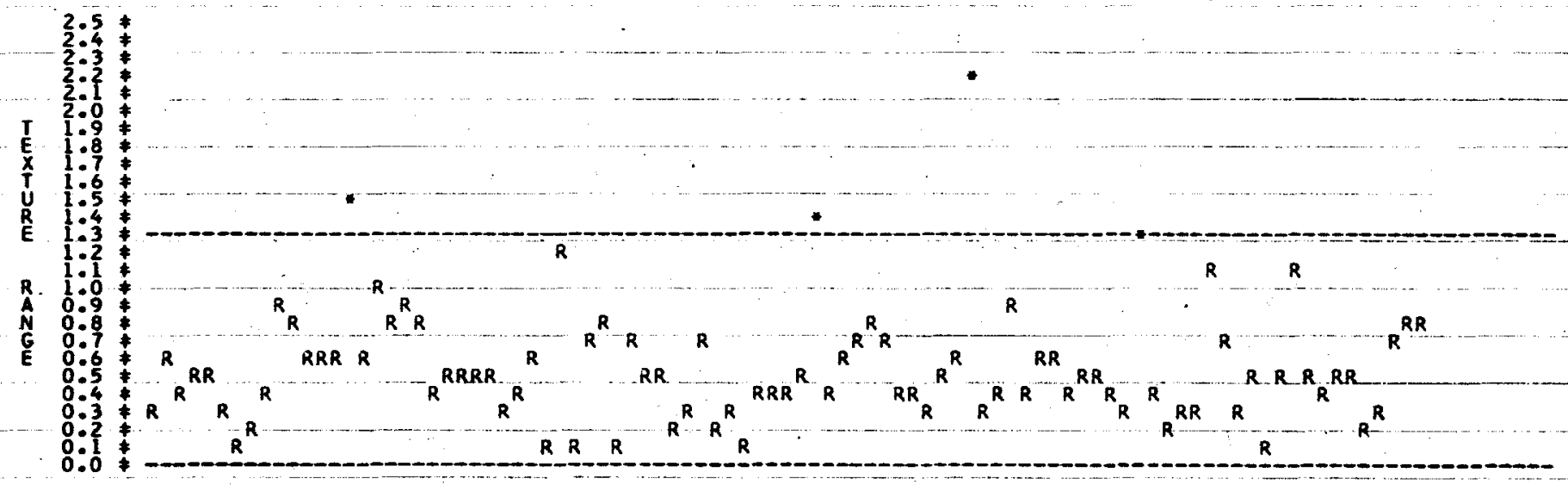




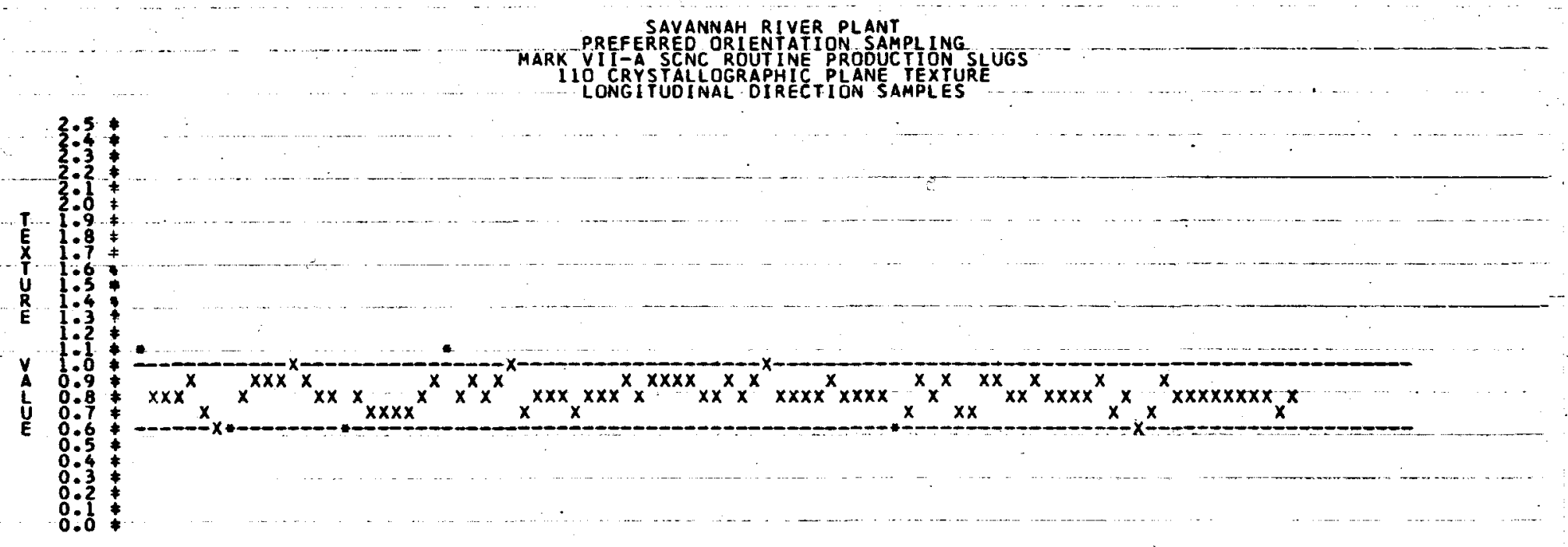

$X$ IS THE ARITHMETIC MEAN OF FOUR SEQUENTIAL SAMPLES

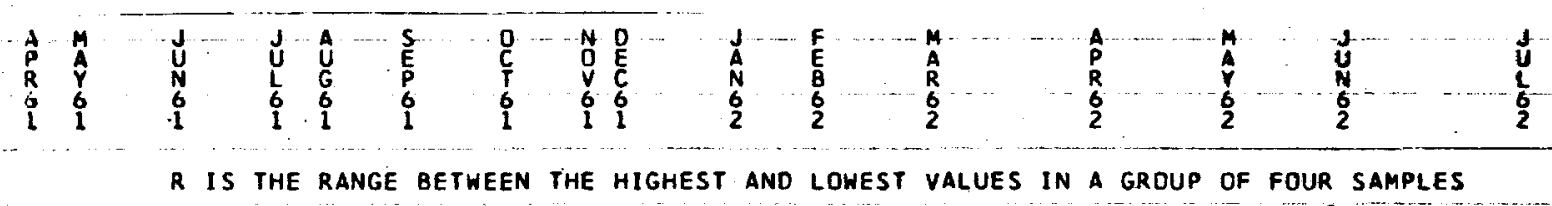

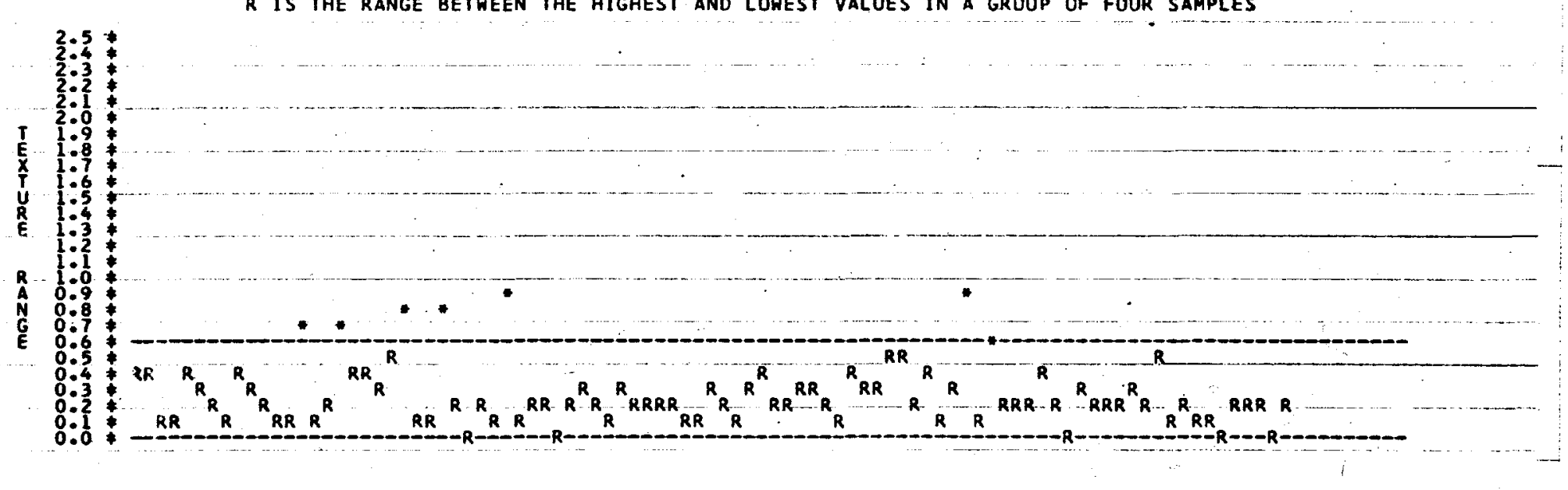




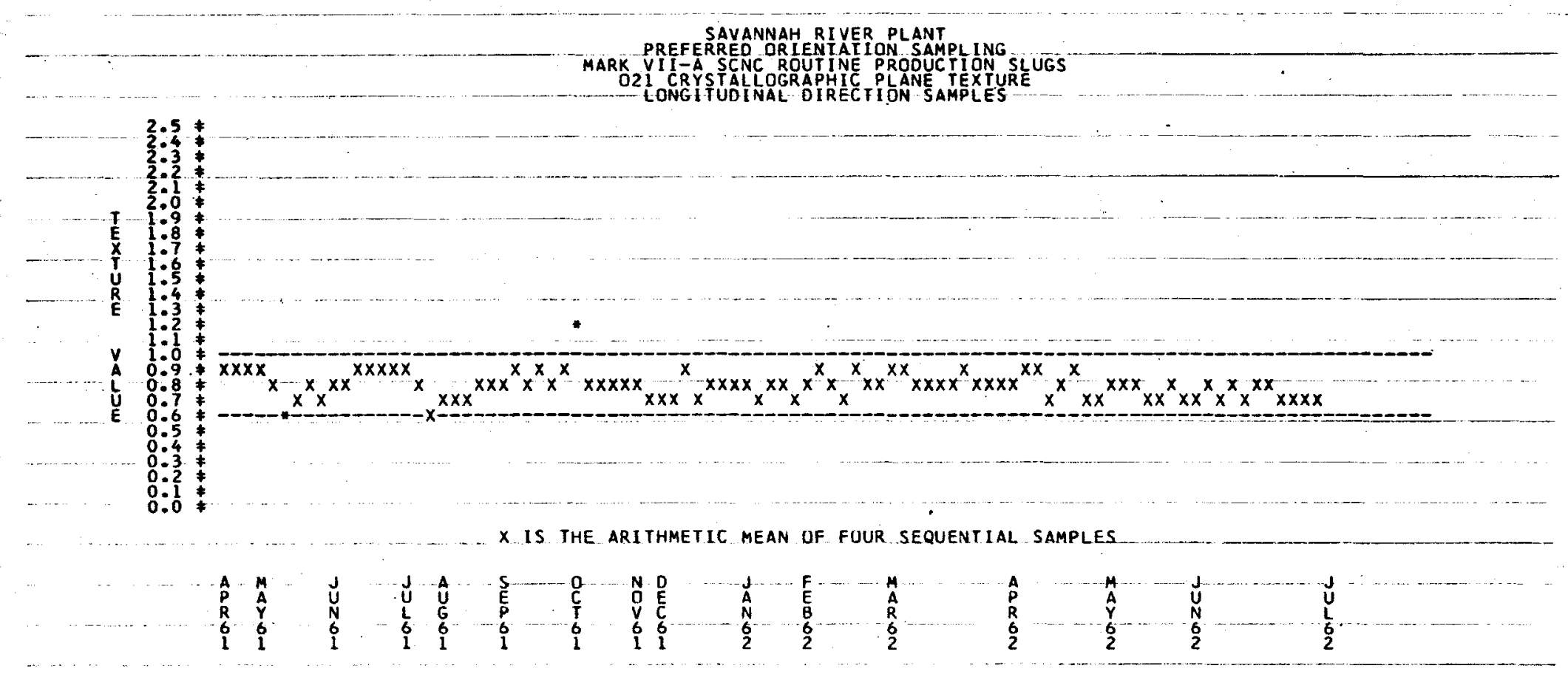

w

$R$ IS THE RANGE BETWEEN THE HIGHEST AND LOWEST VALUES IN A GROUP OF -FOUR SAMPLES
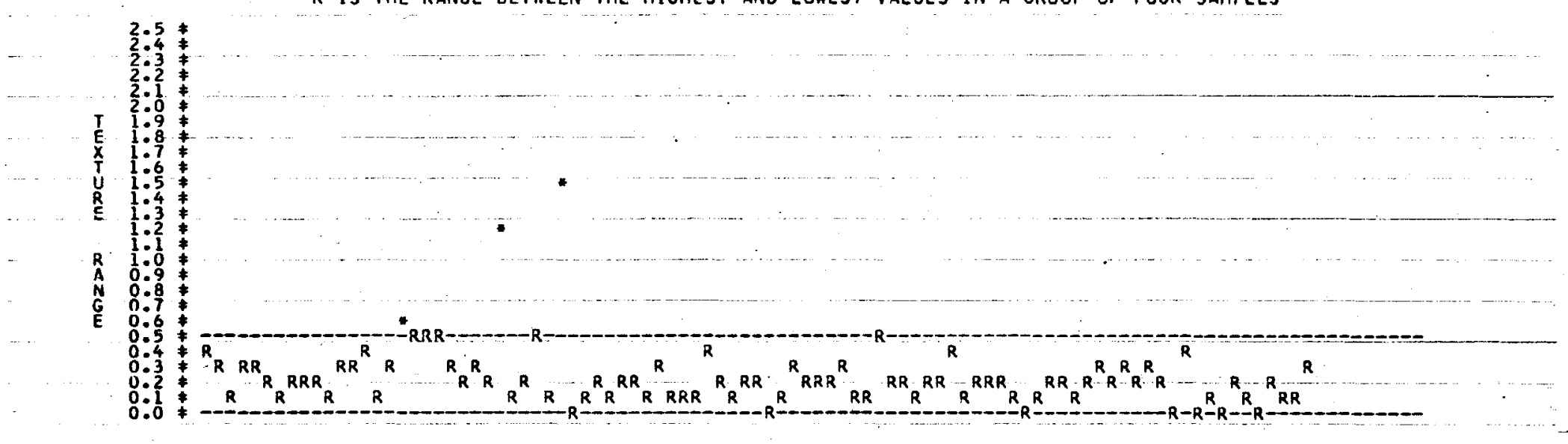


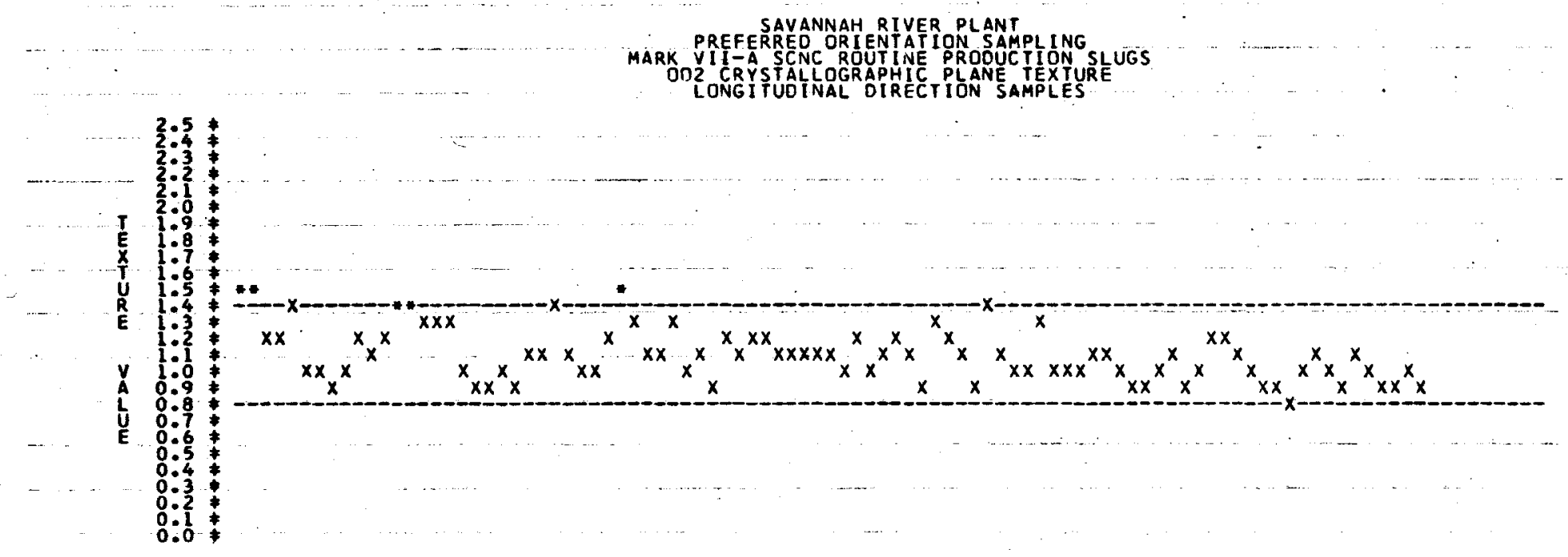

$X$ IS THE ARITHMETIC MEAN OF FOUR SEQUENTIAL SAMPLES

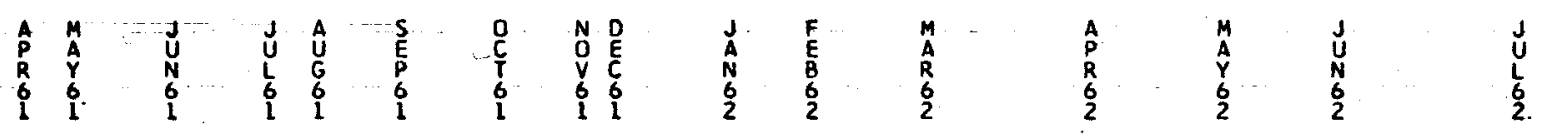

R IS the RANGe BetheEN the highest ano lowest values in a group of four samples

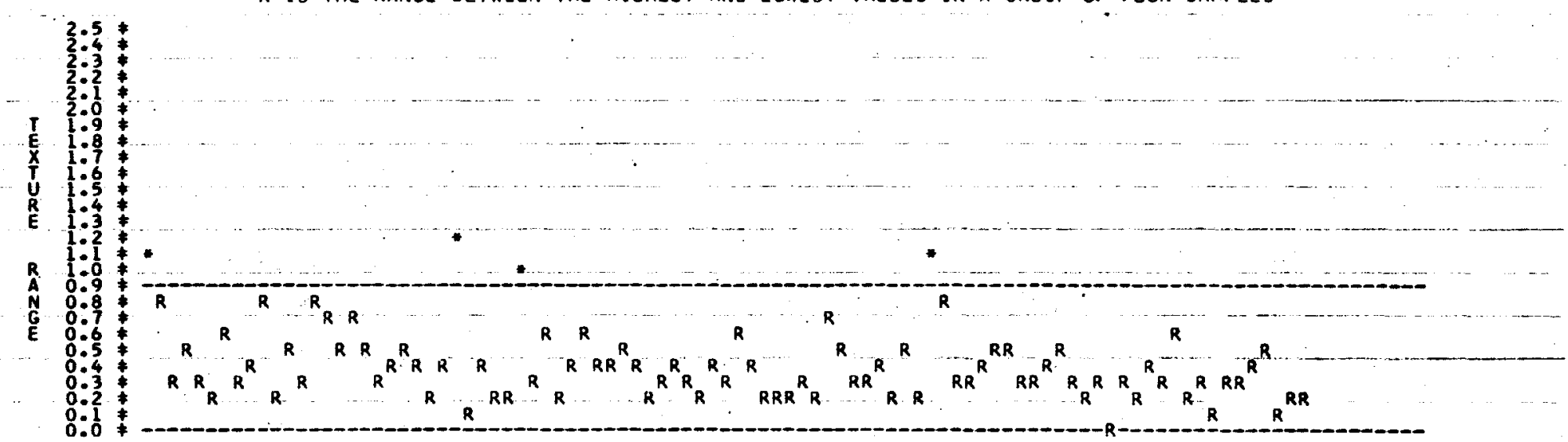




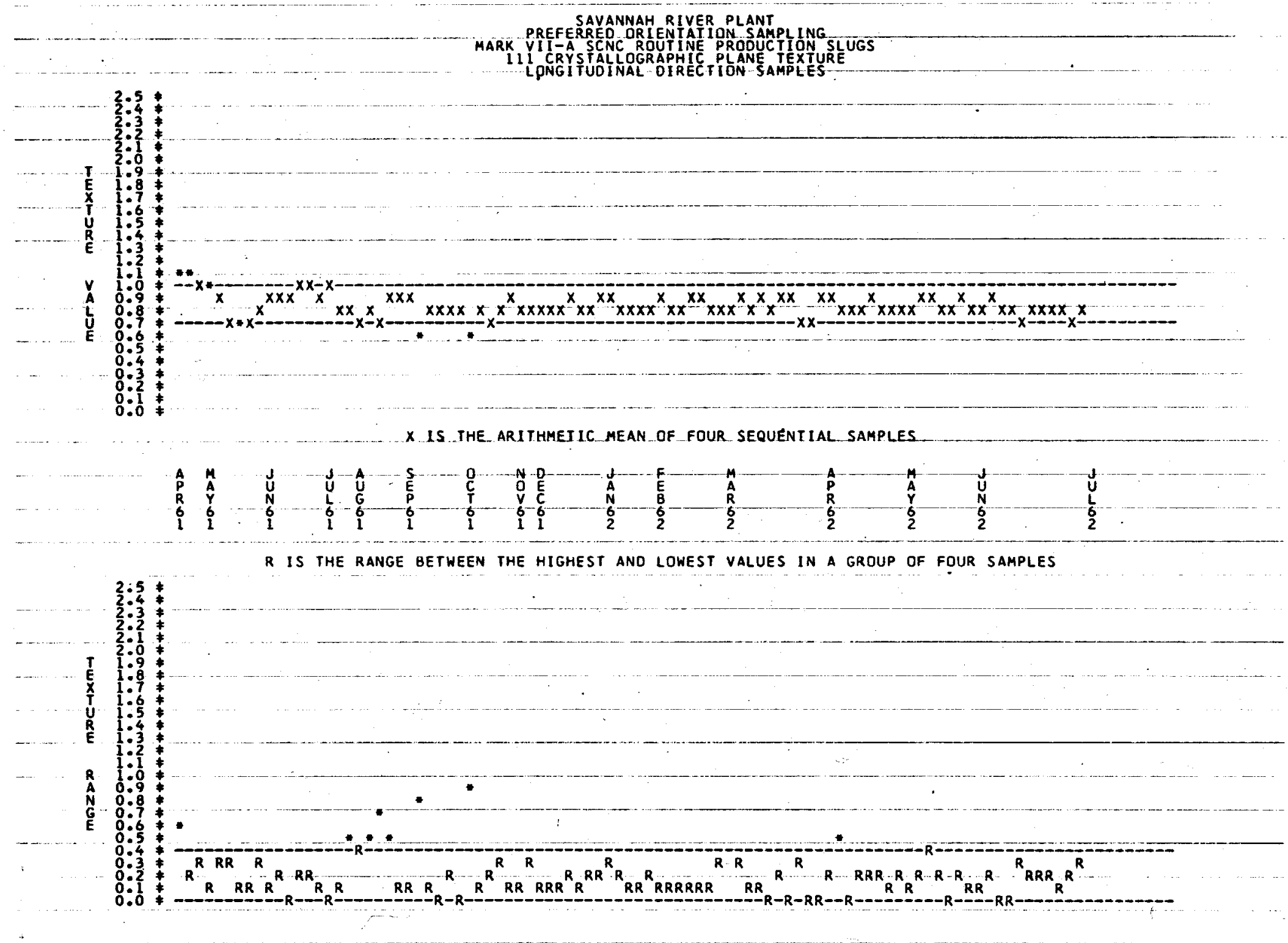




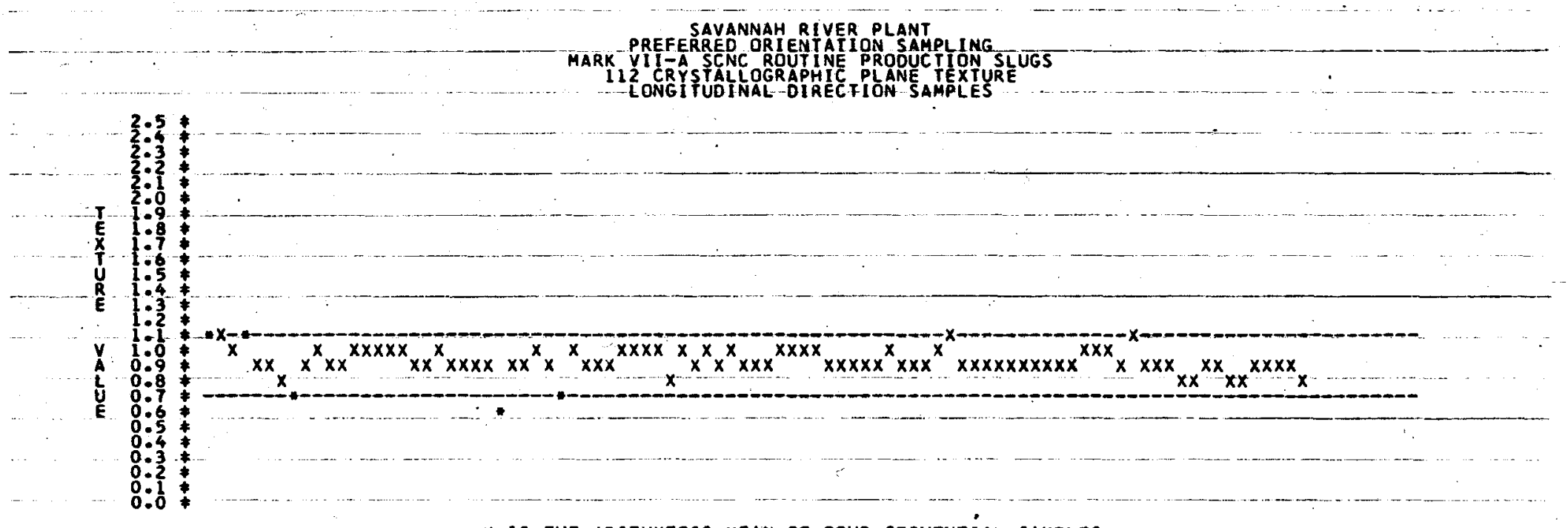

$X$ IS THE ARITHMETIC MEAN OF FOUR SEQUENTIAL SAMPLES

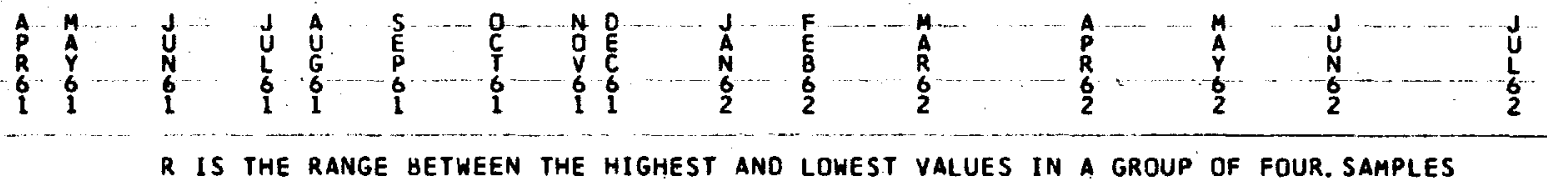

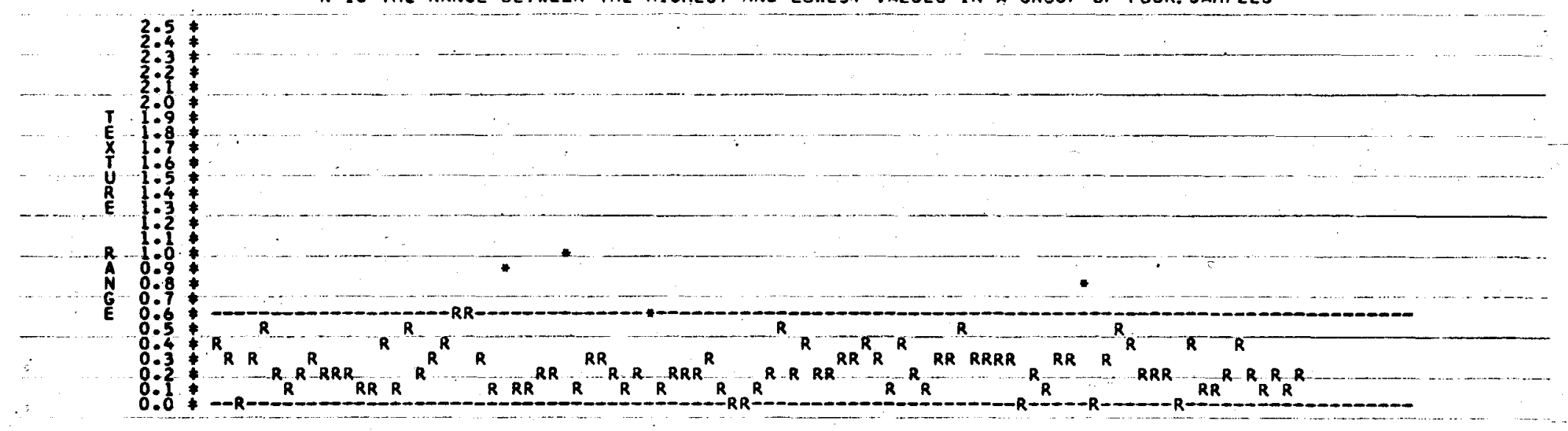




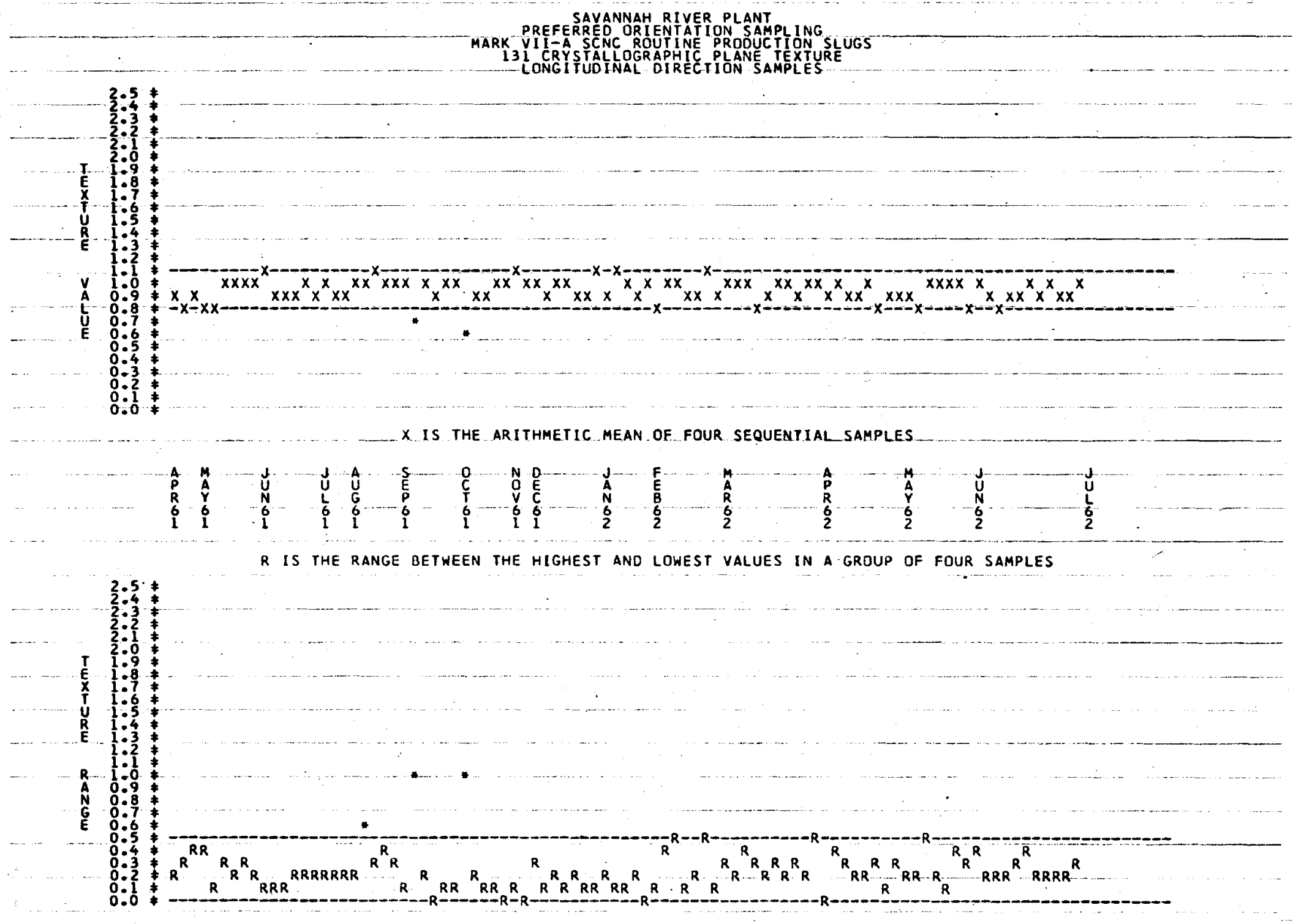




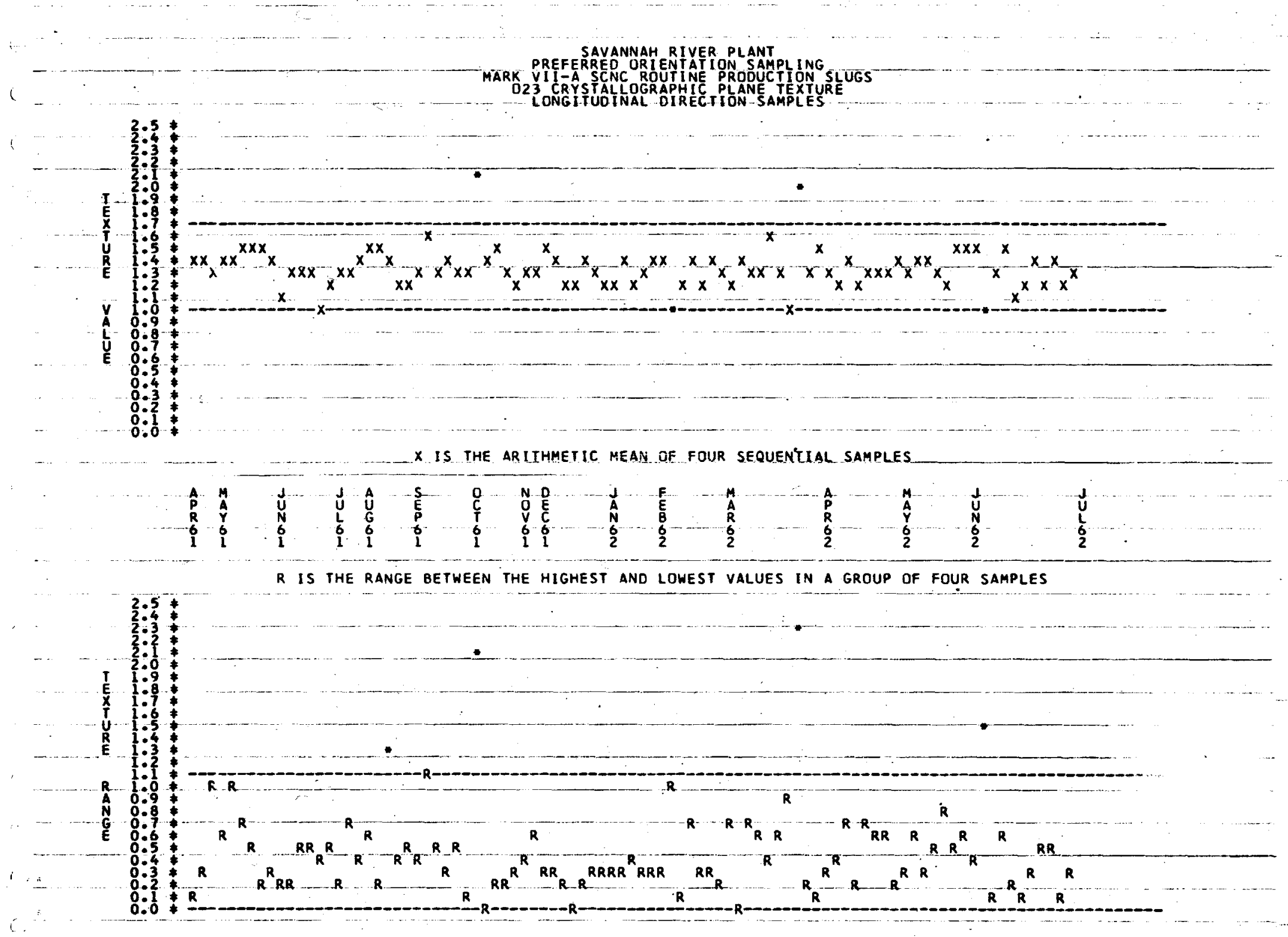




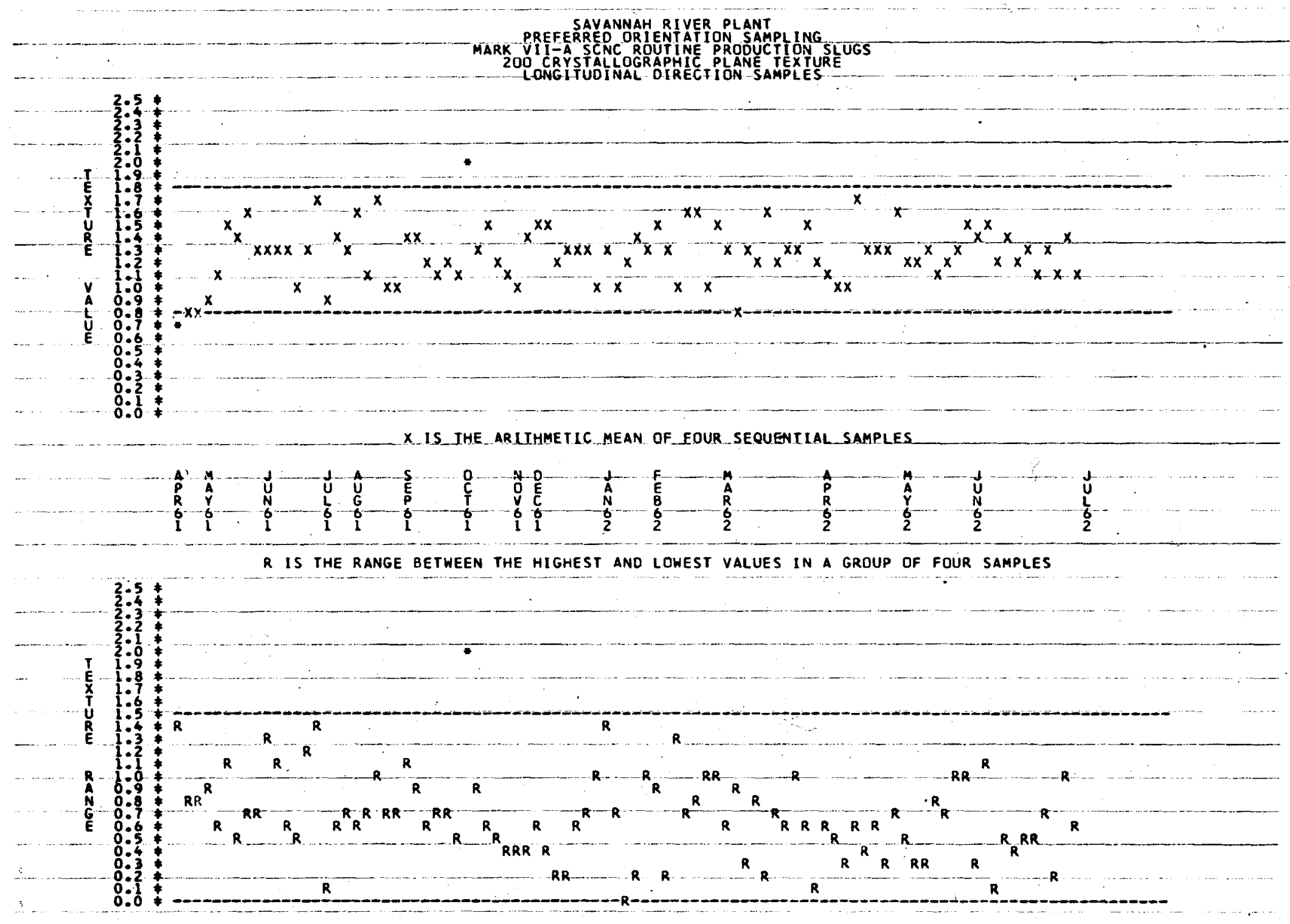




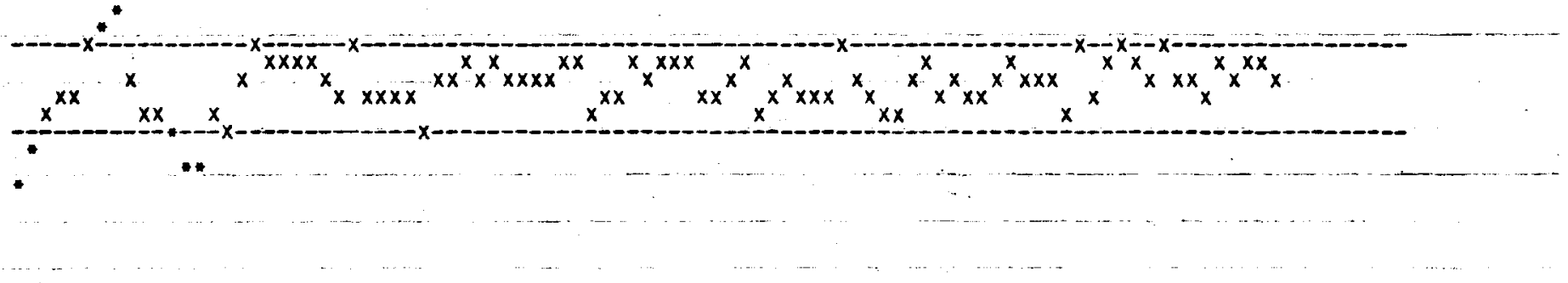

$X$ IS THE ARITHMETIC MEAN OF FOUR SEQUENTIAL SAMPLES

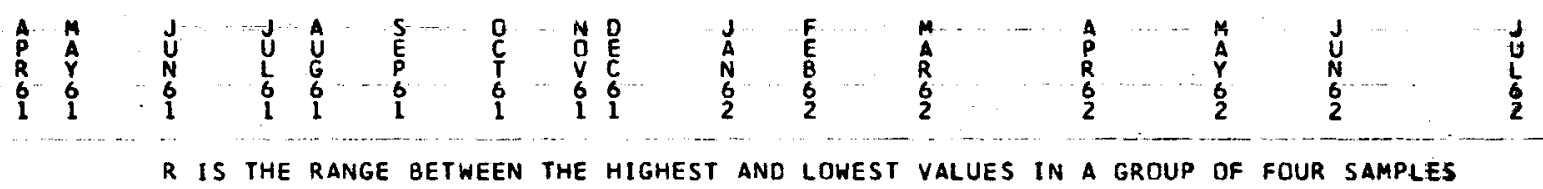

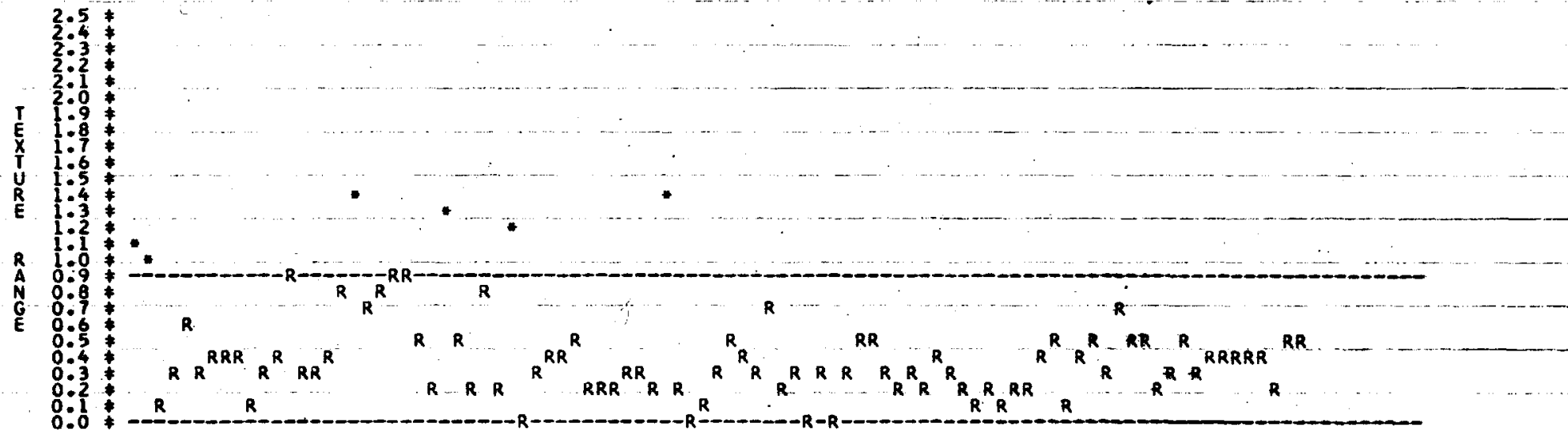




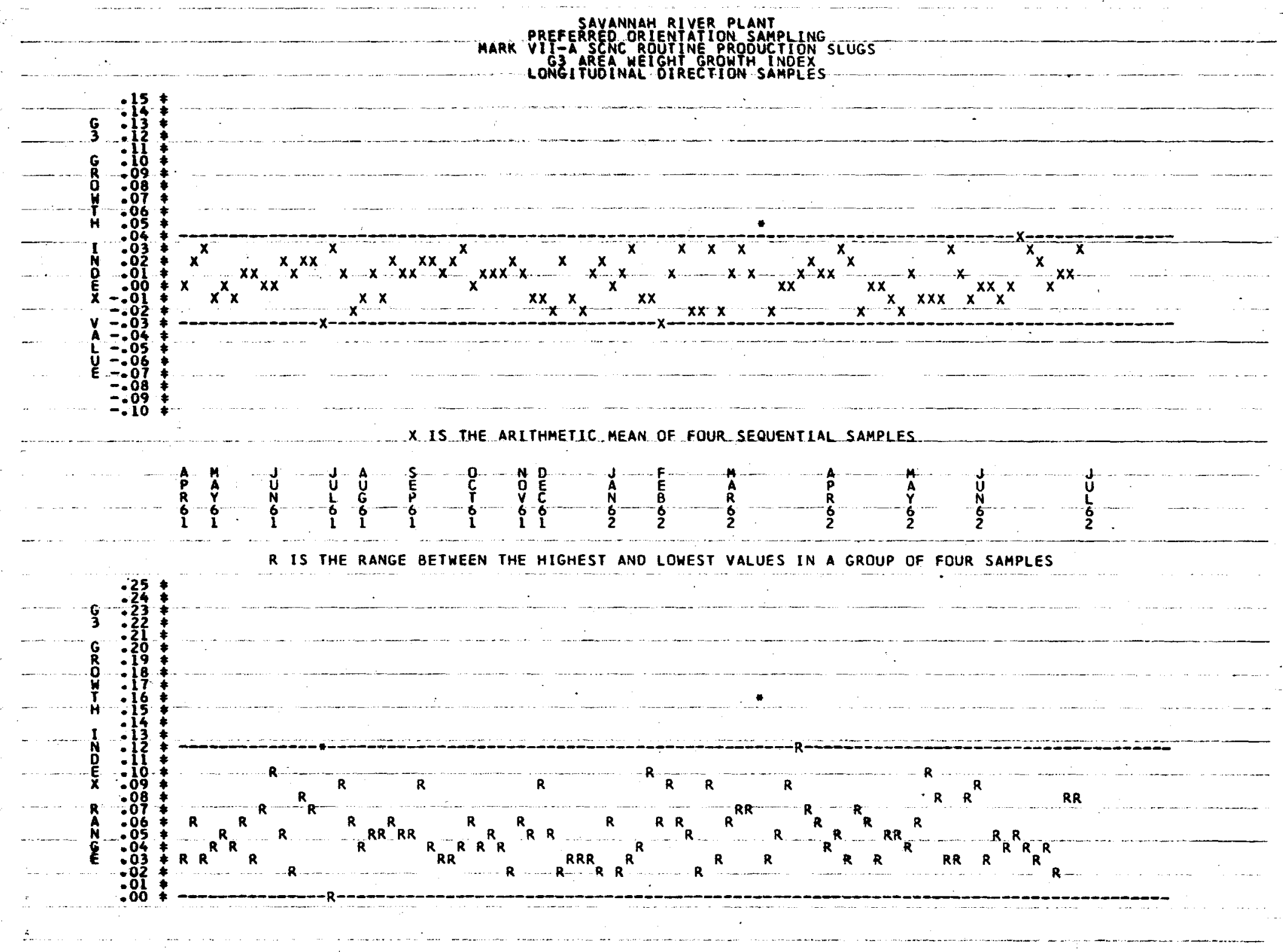




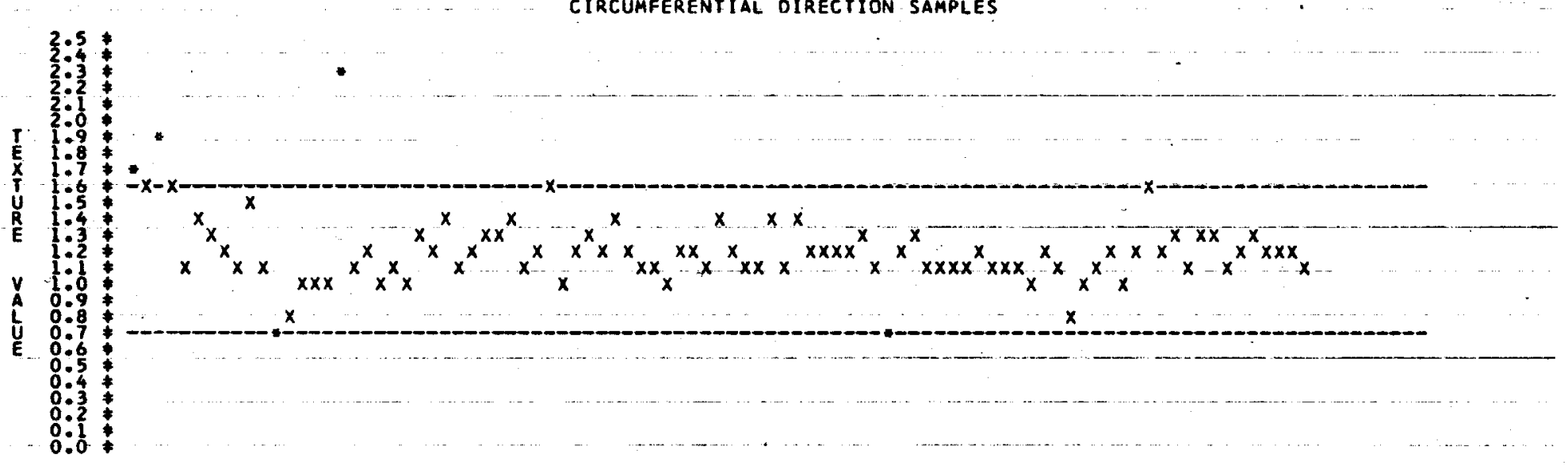

$x$ IS THE ARITHMETIC MEAN OF FOUR SEQUENTIAL SAMPLES

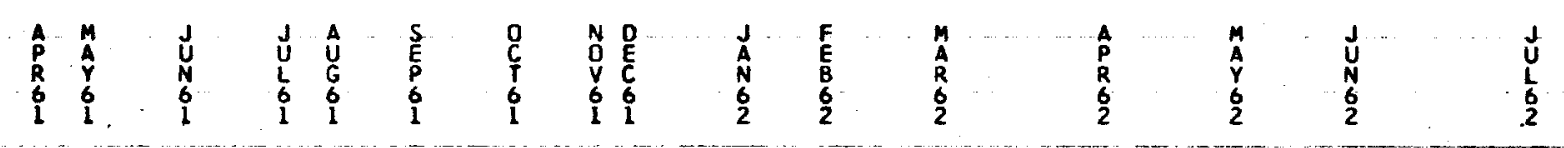

R IS the range between the highest and lowest values in a group of four samples

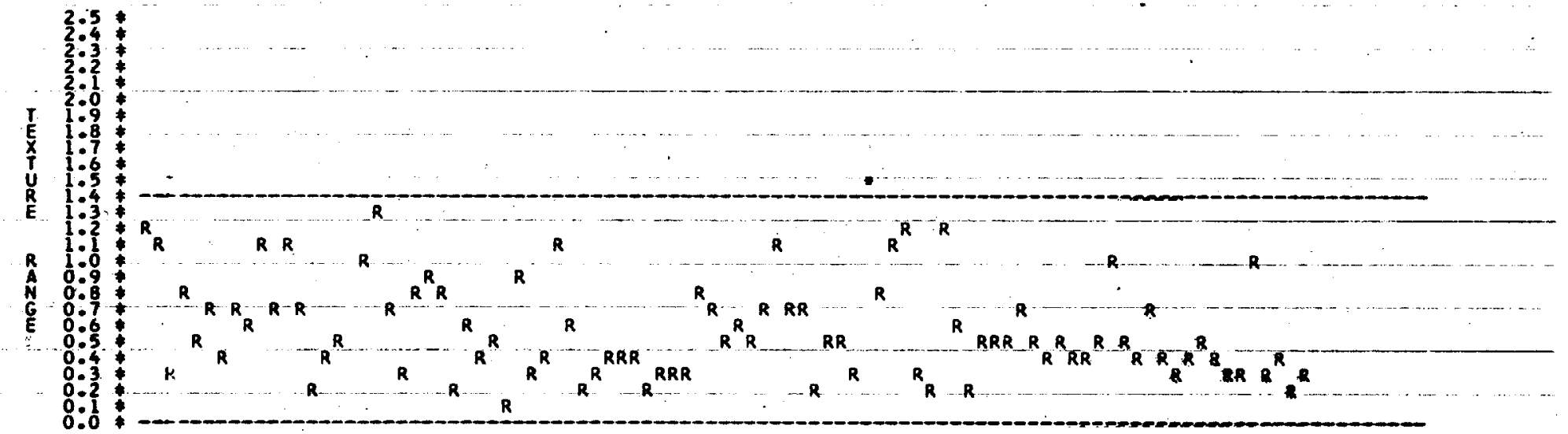




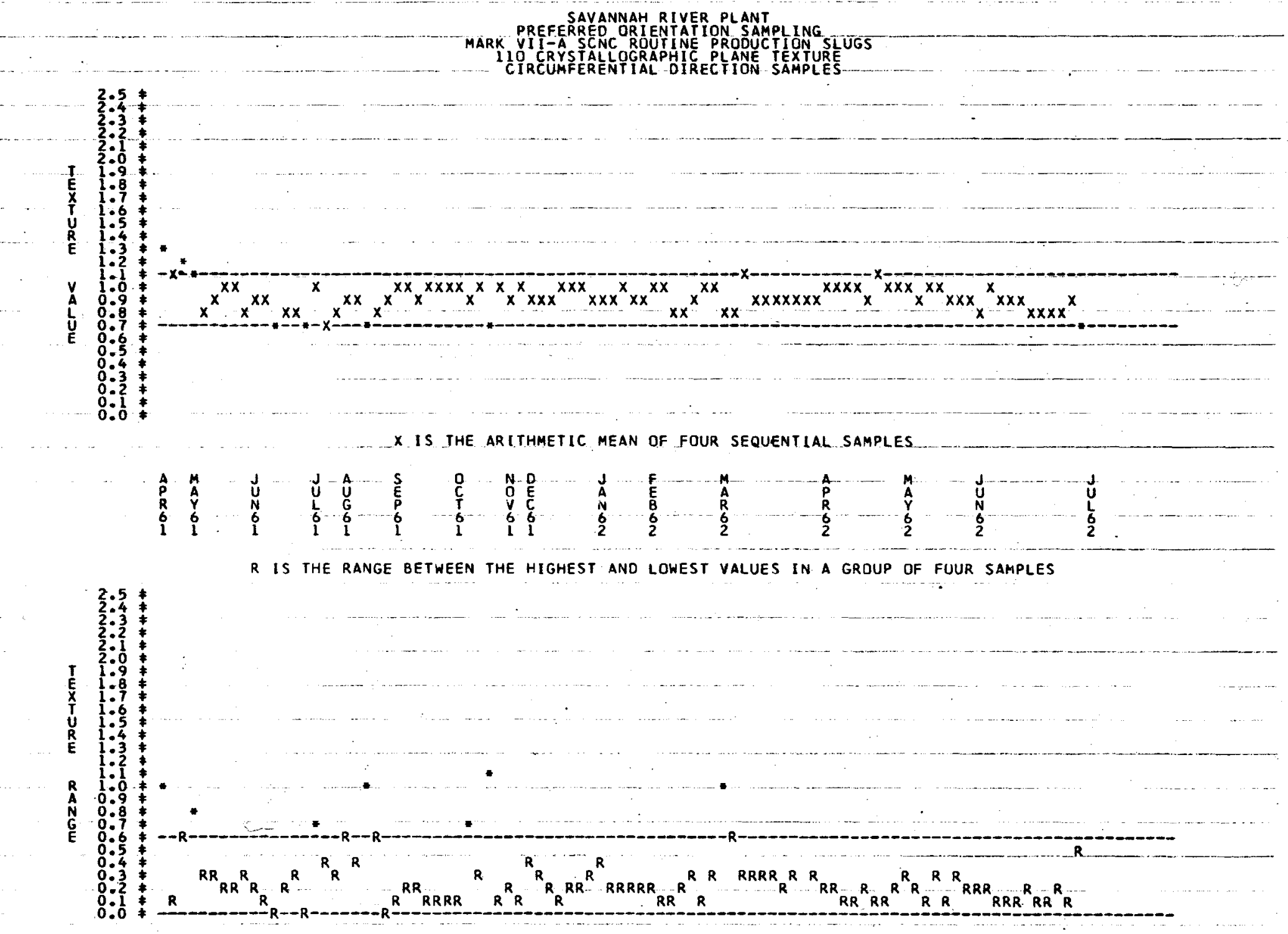




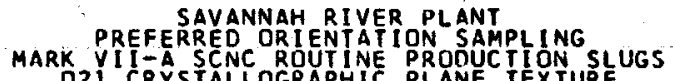

ARK YII-A SCNC ROUTINE PRONUCTION SLUGS
OZI CRYSTALLORAPHIC PLANE TEXIURE
CIRCUMFERENTIAL DIRECTION SAMPLES

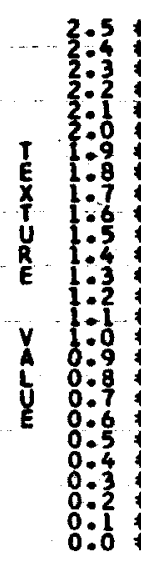

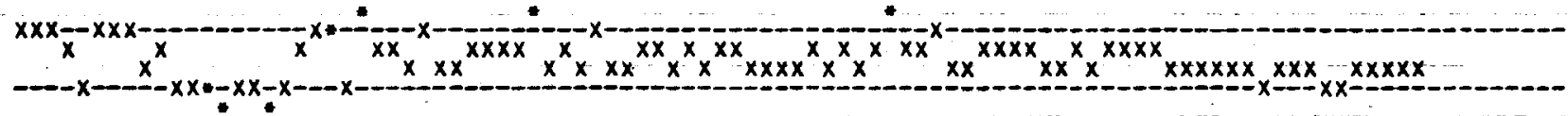

X.. IS THE ARITHMETIC MEAN OF FOUR SEQUENTIAL SAMPLES

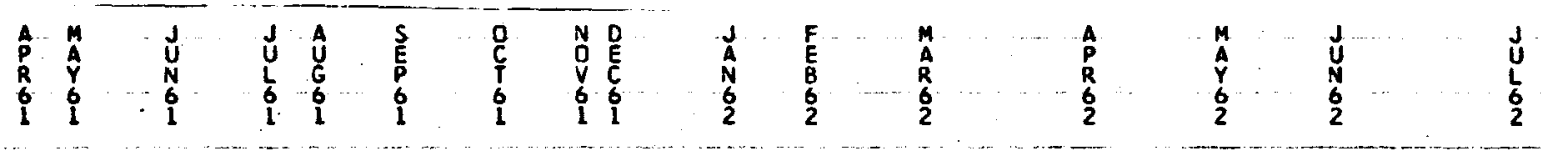

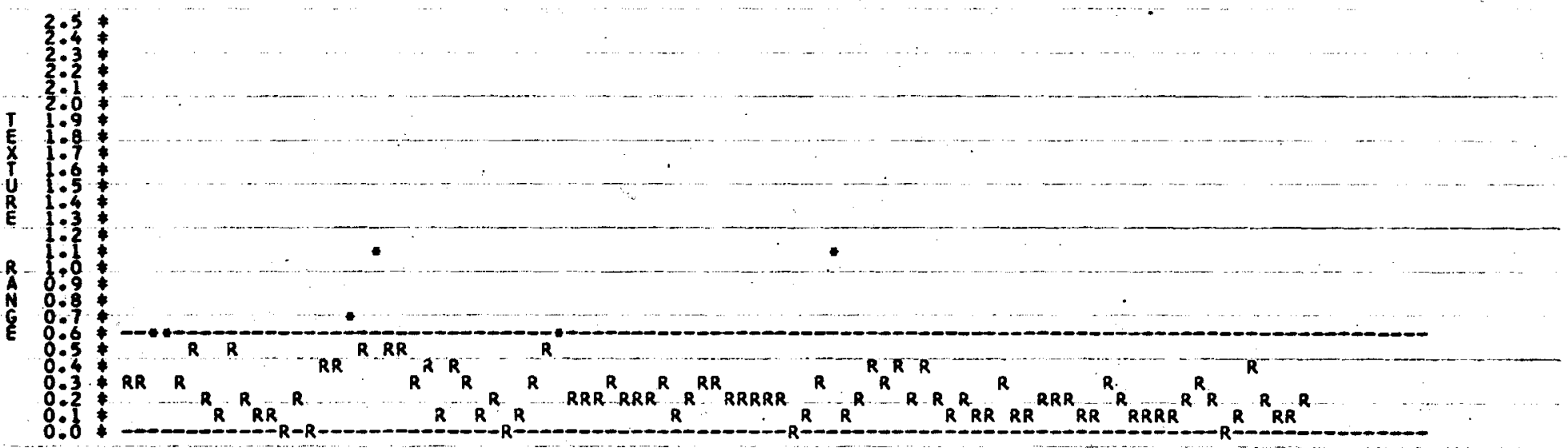



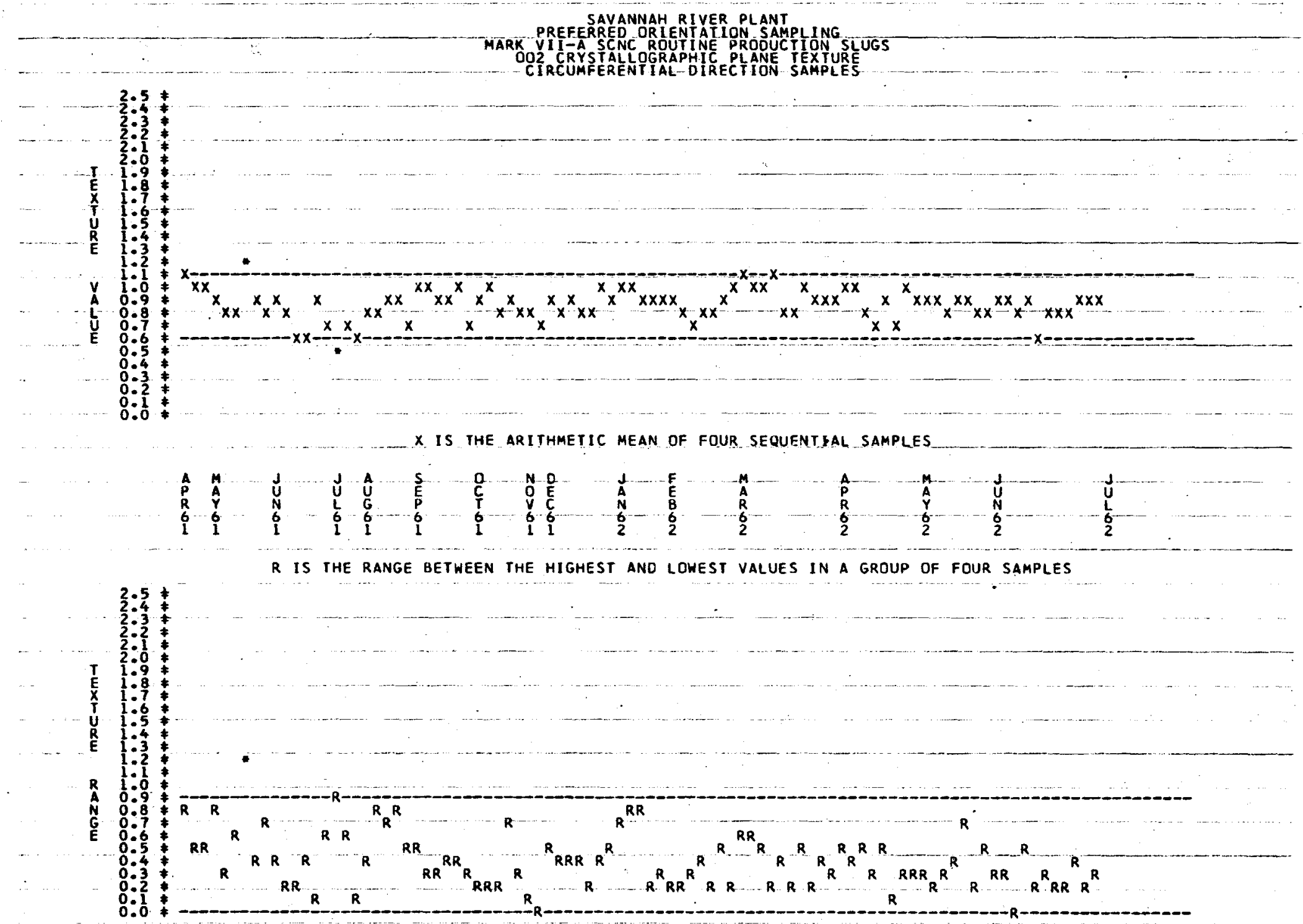


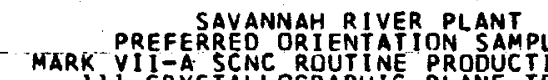

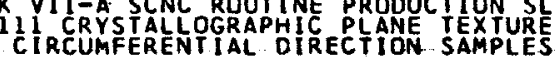

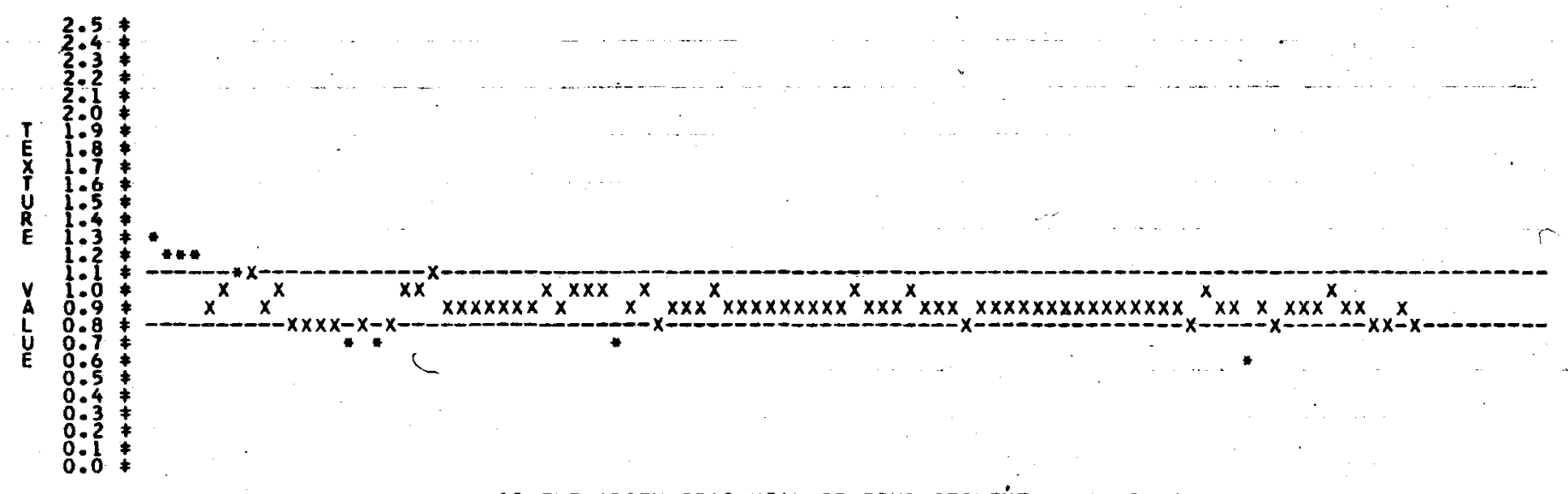

$X$ is the arithmetic mean of four sequenttial samples

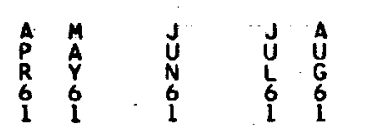
$\begin{array}{lll}0 & N & D \\ C & D & E \\ 0 & N & C \\ 6 & 6 & 6 \\ 1 & 1 & 1\end{array}$
$\begin{array}{ll}J & F \\ A & E \\ N & B \\ 6 & 6 \\ 2 & 2\end{array}$
$\begin{array}{lll}\mathbf{A} & M & \mathbf{H} \\ \mathbf{P} & \mathbf{A} & \mathbf{U} \\ \mathbf{R} & \mathbf{Y} & \mathbf{N} \\ \mathbf{6} & \mathbf{6} & 6 \\ 2 & \mathbf{6} & \mathbf{2}\end{array}$

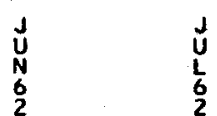

$R$ IS THE RANGe between the highest and lohest Values in a group of four samples

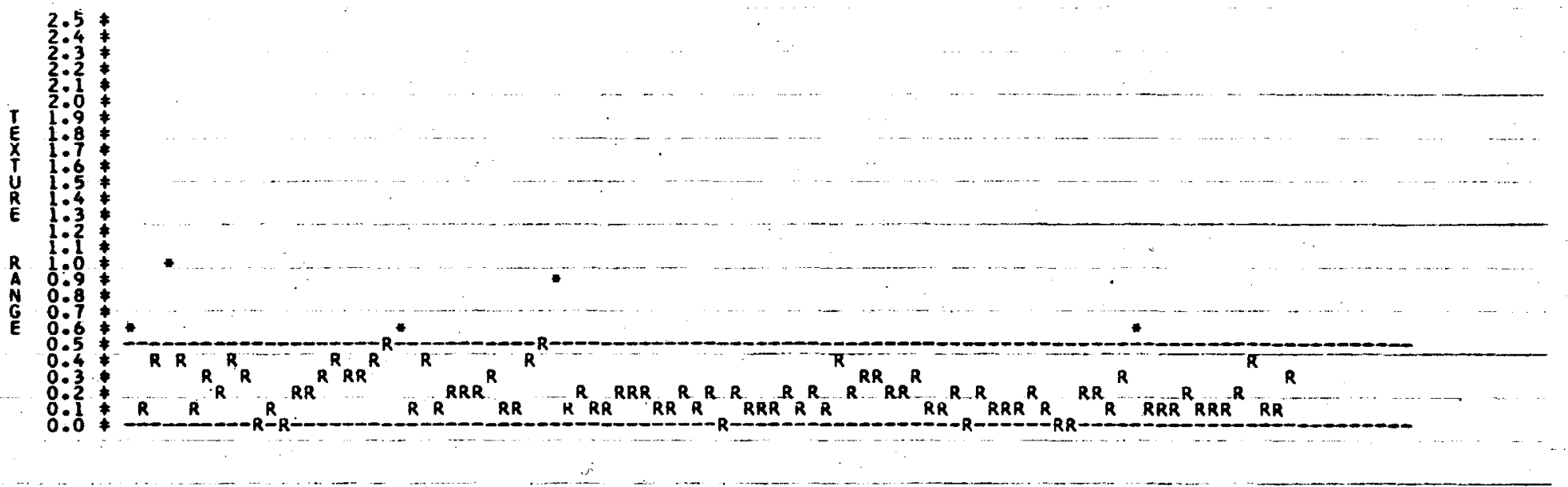




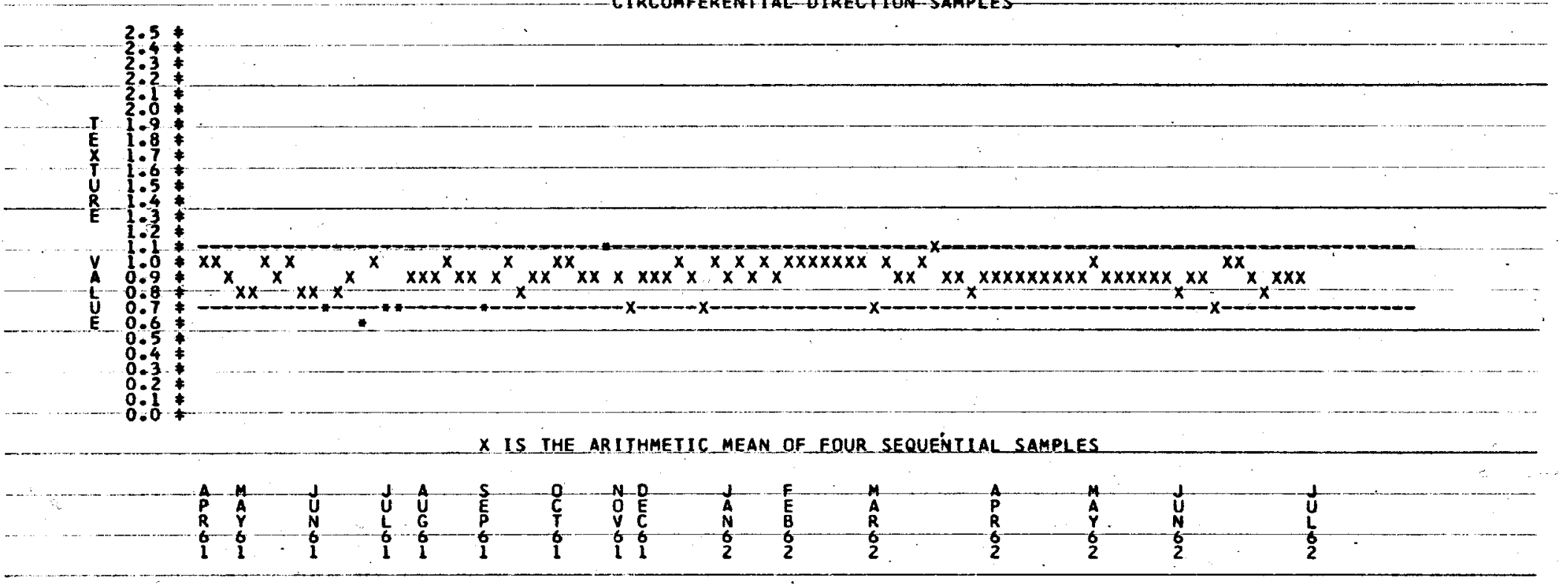

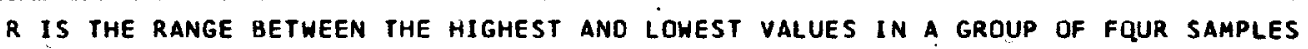

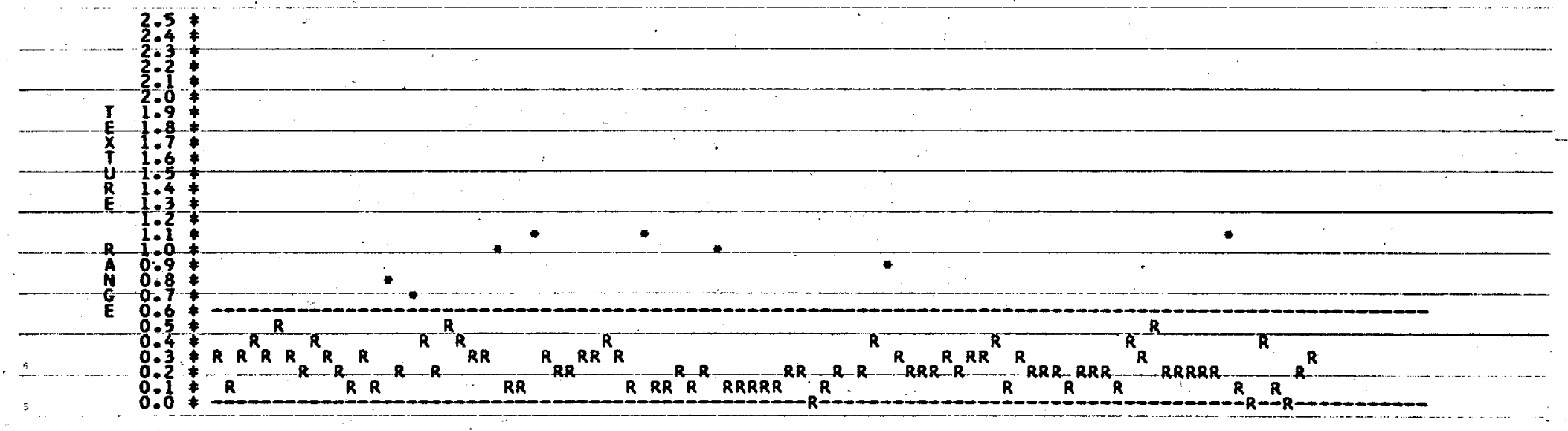




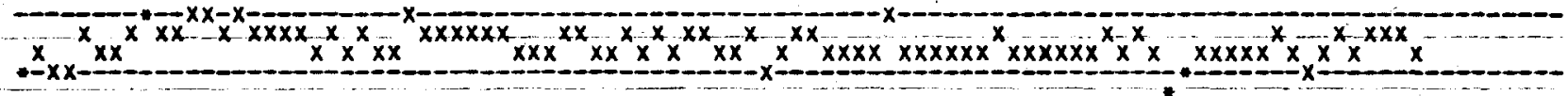

PREFERRED SOAM RIVER PLANT

$-$

(1)

.

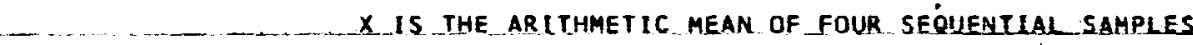

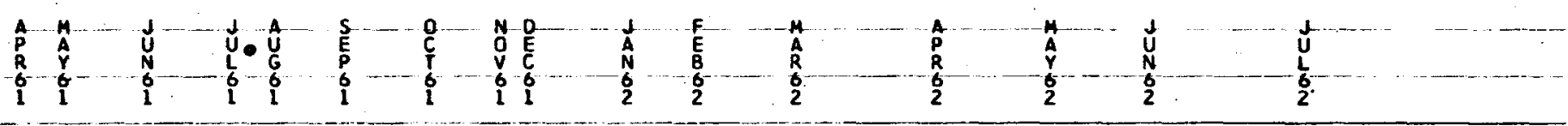

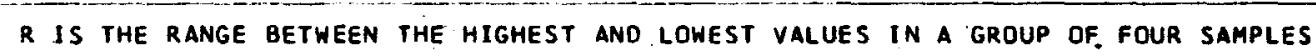

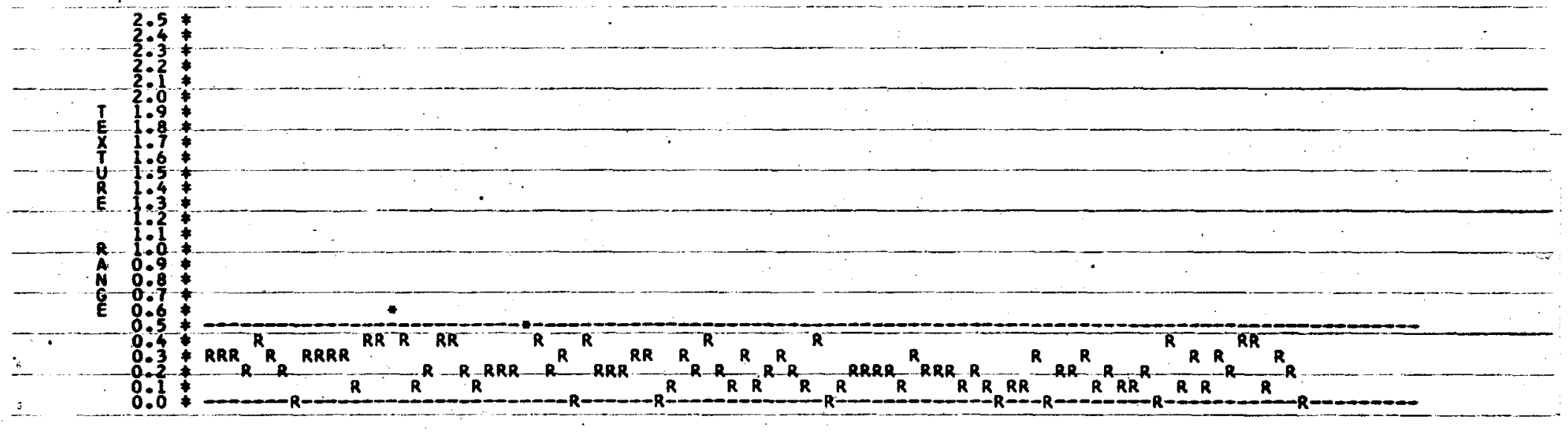




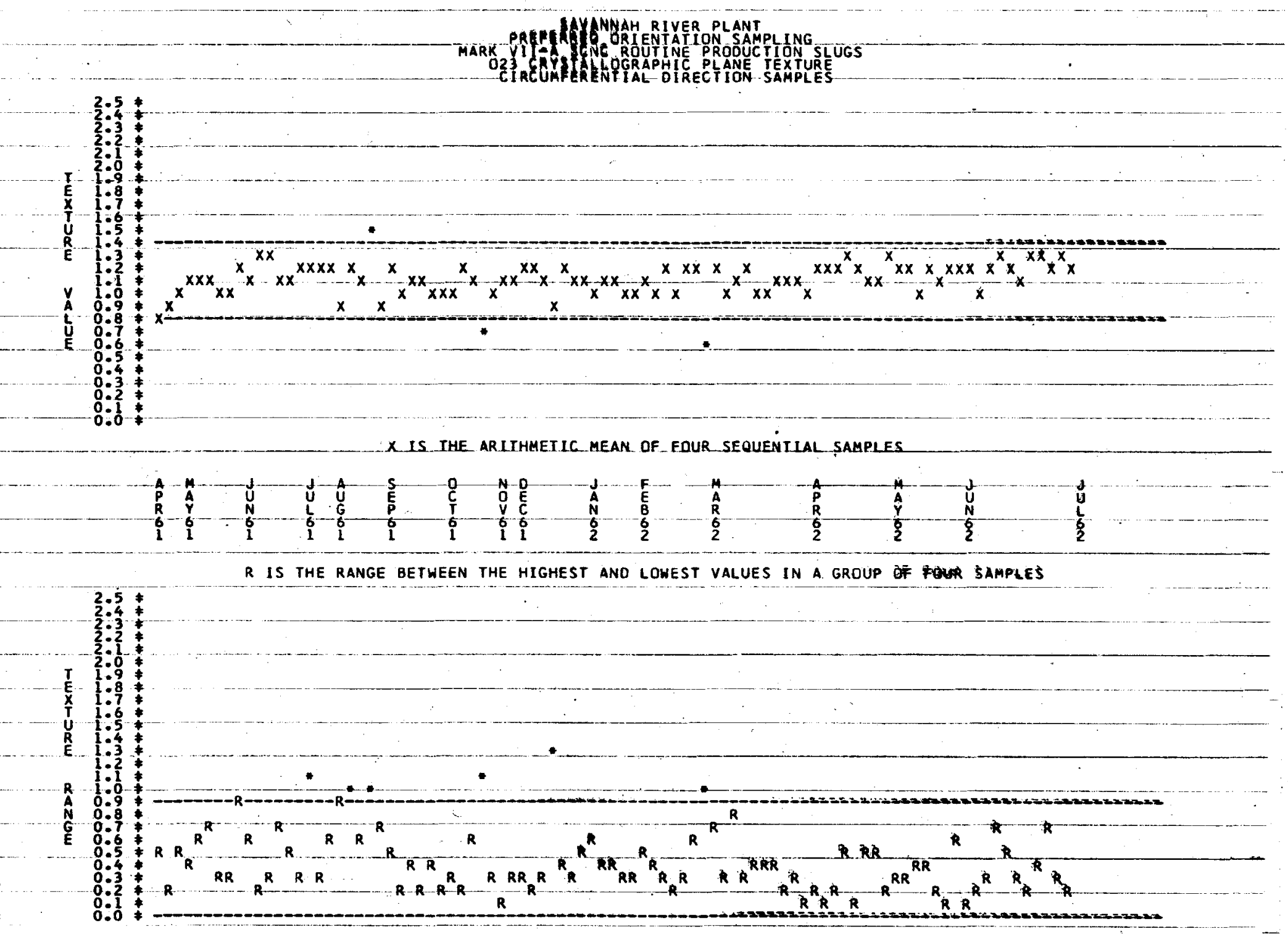




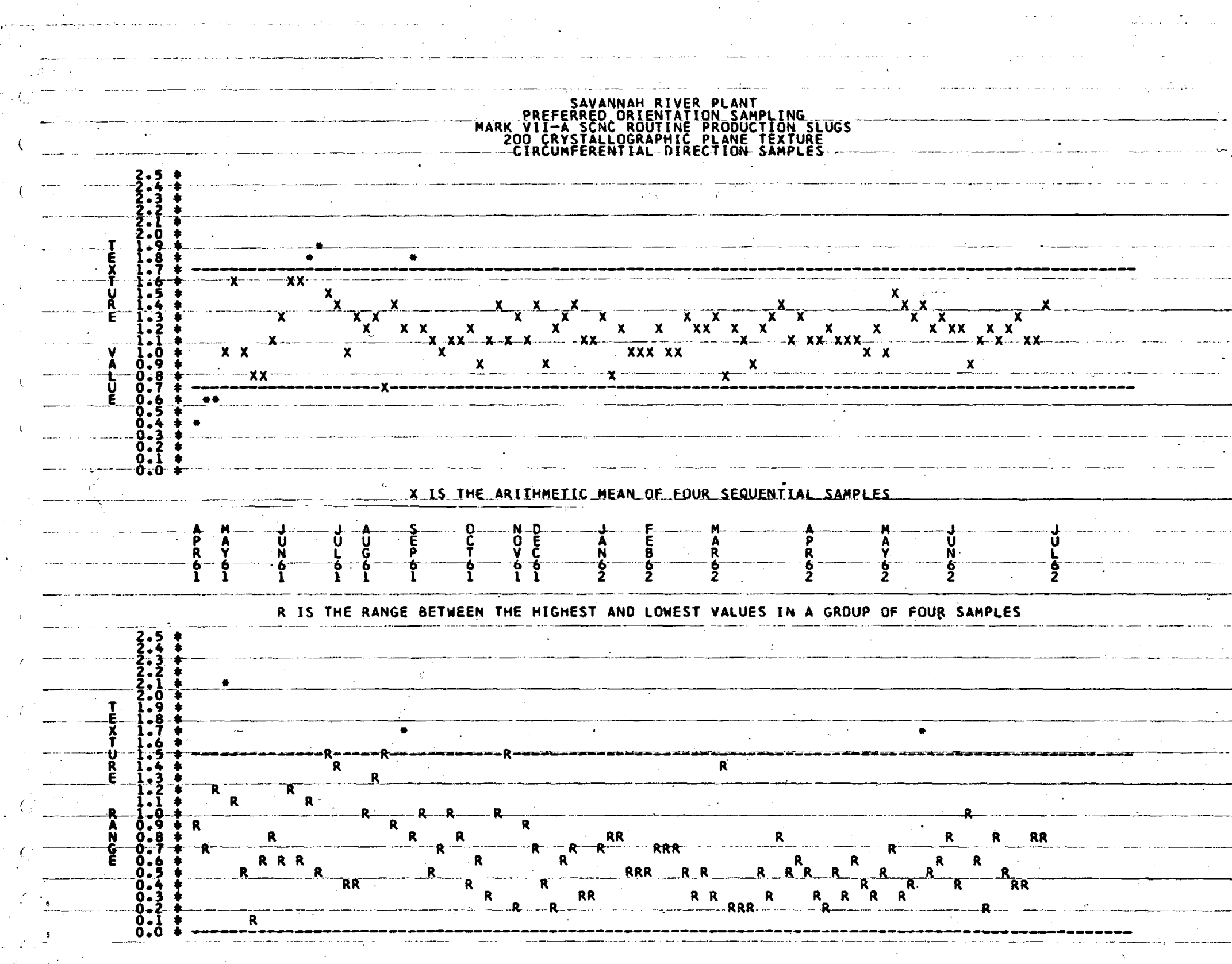




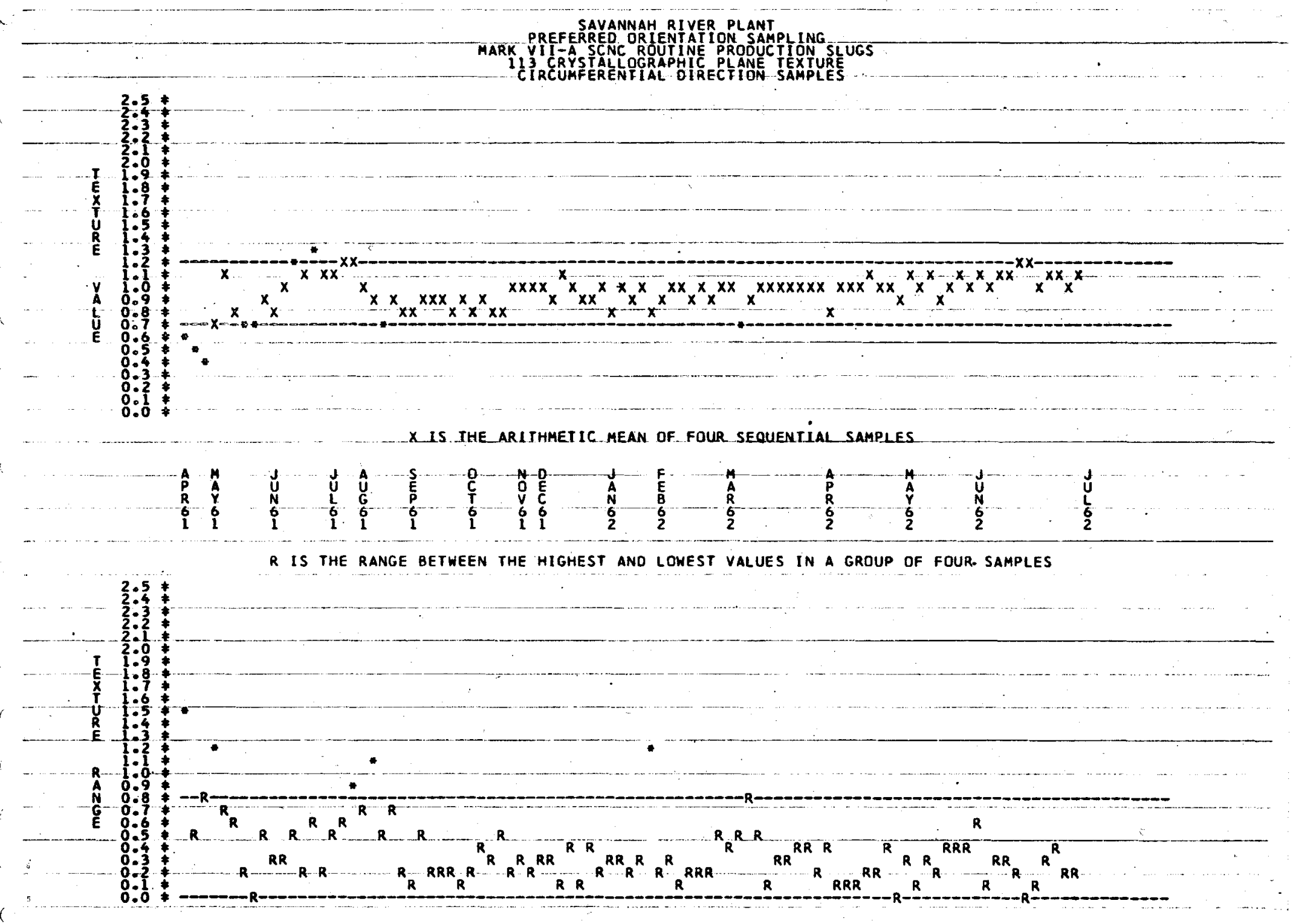




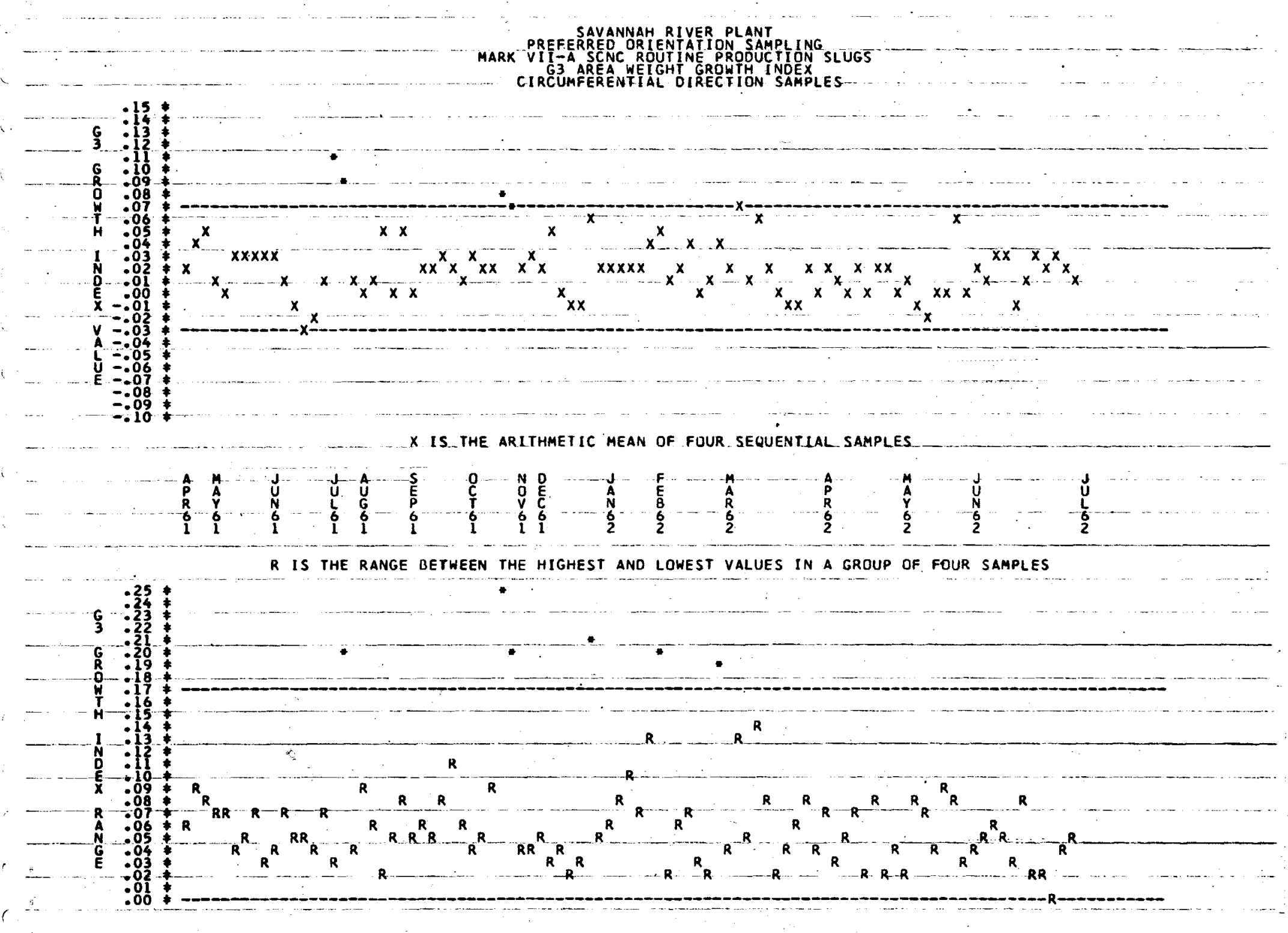

